Ministrv of Economv and Finance

Department of the Treasurv

Analisi e Programmazione

Economico Finanziaria

Working Papers

$N^{\circ} 3-$ April 2018

ISSN 1972-411X

\title{
A stochastic estimated version of the Italian dynamic General Equilibrium Model (IGEM)
}

Nicola Acocella, Giorgio Alleva, Elton Beqiraj, Giovanni Di Bartolomeo, Fabio Di Dio Marco Di Pietro, Francesco Felici, Brunero Liseo

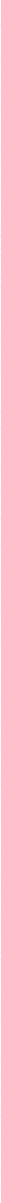




\section{Working Papers}

The working paper series promotes the dissemination of economic research produced in the Department of the Treasury (DT) of the Italian Ministry of Economy and Finance (MEF) or presented by external economists on the occasion of seminars organized by MEF on topics of institutional interest to the DT, with the aim of stimulating comments and suggestions.

The views expressed in the working papers are those of the authors and do not necessarily reflect those of the MEF and the DT.

\section{(C) Copyright:}

2018, Nicola Acocella, Giorgio Alleva, Elton Beqiraj, Giovanni Di Bartolomeo, Fabio Di Dio Marco Di Pietro, Francesco Felici, Brunero Liseo.

The document can be downloaded from the Website www.dt.tesoro.it and freely used, providing that its source and author(s) are quoted. 


\section{CONTENTS}

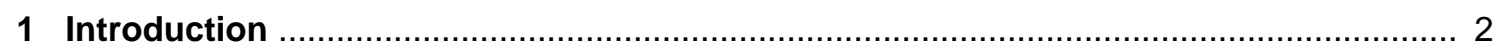

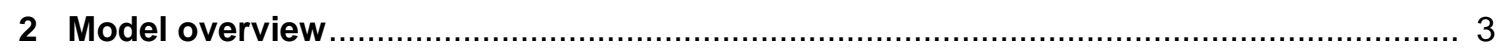

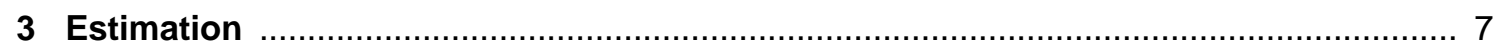

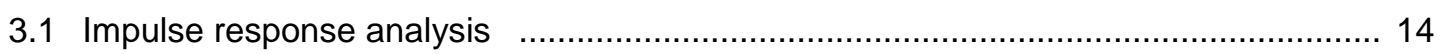

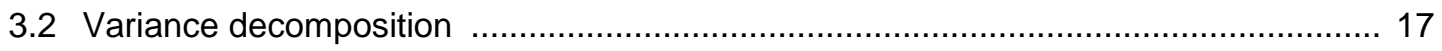

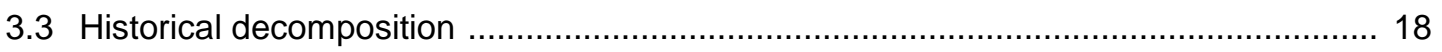

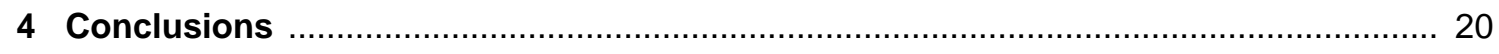

Appendix A - The IGEM model

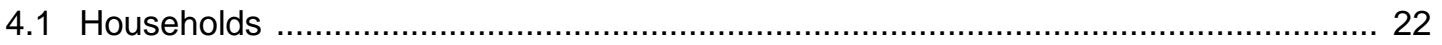

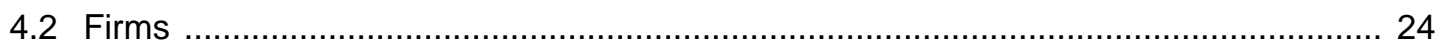

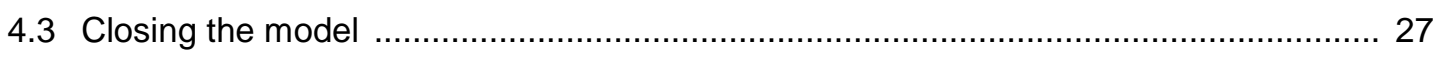

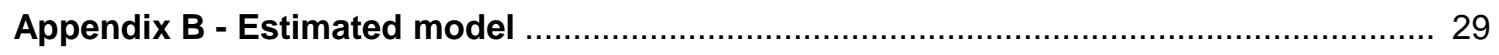

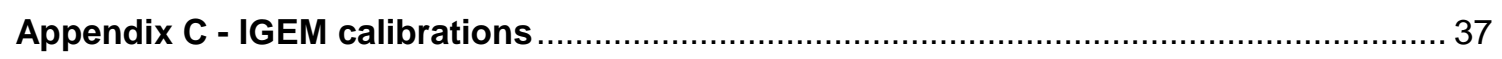

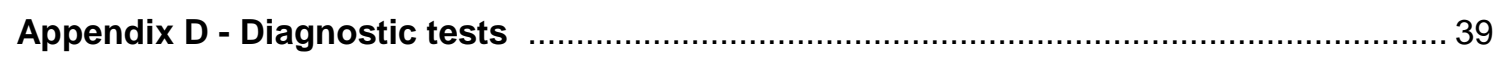

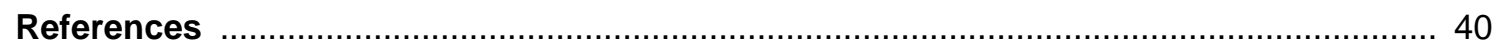





\title{
A stochastic estimated version of the Italian dynamic General Equilibrium Model (IGEM)*
}

\author{
Nicola Acocella ${ }^{1}$, Giorgio Alleva ${ }^{1,2}$, Elton Beqiraj ${ }^{3}$, Giovanni Di Bartolomeo ${ }^{3}$, Fabio Di Dio ${ }^{4}$, \\ Marco Di Pietro ${ }^{3}$, Francesco Felici ${ }^{5}$, Brunero Liseo ${ }^{1}$
}

\begin{abstract}
We estimate with Bayesian techniques the Italian dynamic General Equilibrium Model (IGEM), which has been developed at the Italian Treasury Department, Ministry of Economy and Finance, to assess the effects of alter-native policy interventions. We analyze and discuss the estimated effects of various shocks on the Italian economy. Compared to the calibrated version used for policy analysis, we find a lower wage rigidity and higher adjustment costs. The degree of prices and wages indexation to past inflation is much smaller than the indexation level assumed in the calibrated model. No substantial difference is found in the estimated monetary parameters. Estimated fiscal multipliers are slightly smaller than those obtained from the calibrated version of the model.
\end{abstract}

JEL Classification: E27, E30, E60.

Keywords: Dynamic General Equilibrium Model, Bayesian estimation, Simulation Analysis, Italy.

\footnotetext{
" The authors thank an anonymous referee, Riccardo Barbieri Hermitte, Mauro Bernardi, Alessia Franzini, Ersilia Incelli, Bianca Giannini, Francesco Nucci, Libero Monteforte, Carolina Serpieri, Lea Petrella, Michele Raitano, and Andrea Tancredi for comments on previous versions.

${ }^{1}$ Department of Methods and Models for Economics, Territory and Finance, Sapienza University of Rome.

2 Italian National Institute of Statistics.

${ }^{3}$ Department of Economics and Law, Sapienza University of Rome.

${ }^{4}$ Sogei - Macroeconomic Models Division.

${ }^{5}$ Department of the Treasury - Italian Ministry of Economy and Finance.
} 


\section{Introduction}

This paper estimates a linear stochastic version of the Italian dynamic General Equilibrium Model (IGEM). The theoretical model has been developed at the Italian Treasury Department, Ministry of Economy and Finance, to evaluate the effects of alternative policy interventions and fiscal consolidation packages in Italy. It was originally formalized by Annicchiarico et al. (2013a). Instead, this paper focuses on the model's estimation.

The model developed by the Treasury has been designed to capture specific features of the Italian economy. It formalizes a segmented labor market, where different contract types coexist, and links limited asset market participation to working contracts. Specifically, IGEM formalizes a dual labor market where some workers exhibit large union coverage, strong job insurance protection, and high firing costs, while for others we find minimal or no union membership, weak security protection, and low firing costs. Weak labor contracts prevent some households from participating in the asset market, and thus from sharing the risk associated with labor income fluctuations.

IGEM has been used to evaluate the macroeconomic impact of structural reforms and policy interventions and to study the impact of fiscal devaluation policies on the Italian economy. By calibrating the model, Annicchiarico et al. (2015) find, for instance, that fiscal devaluation policies are likely to produce slight improvements in the external position of the economy only in the short-run, whereas output gains appear to persist in the long-run. They also find that taxation on consumption tends to be regressive; therefore, the distributional effects across households associated with fiscal policies tends to be non-negligible.

The importance of the estimation of medium scale DSGE models and a clear defense of DSGE estimation techniques against recent criticisms are provided, among others, by Christiano et al. (2017). ${ }^{1}$ The evaluation of policy reforms and our understanding of the propagation mechanism of structural shocks need to be based on estimated models; therefore, IGEM requires to be placed in a stochastic framework and estimated.

\footnotetext{
${ }^{1}$ In general, after the remarkable progress in their specification and estimation, DSGE models have proved their ability to fit the data and their usefulness as policy tools. Smets and Wouters (2003) and Adolfson et al. (2007), provide evidence that a New Keynesian model could track and forecast time series better than a vector autoregression estimated with Bayesian techniques (BVAR). Christiano et al. (2005, 2010) show that an optimization-based model with nominal and real frictions could successfully explain the effects of a monetary policy shock.
} 
Our strategy to take IGEM to the data proceeds as follows. After incorporating the stochastic structure in IGEM and linearizing it, we estimate the model on Italian data by using Bayesian estimation techniques. To capture the unit root character of macroeconomic time series, we allow a stochastic trend in total factor productivity (TFP). Our estimated DSGE model has then been used to explore the impacts of various shocks on the Italian economy.

We analyze the impulse responses of the main economic variables to structural shocks and the uncertainty surrounding these effects. The size of the shocks is, in fact, determined by the posterior estimate of one standard deviation shock, i.e., we use the full joint posterior distribution of structural parameters and shocks to produce the Bayesian uncertainty bounds of the IRFs. To study the effectiveness of stabilization policies, we also extend IGEM to incorporate active monetary and fiscal policy rules in the original model.

Compared to the calibrated version of model, we find: a lower wage rigidity and higher adjustment costs; greater investment and labor adjustment costs; a much smaller degree of prices and wages indexation to past inflation; no substantial difference in the estimated monetary parameters, which are in line with the standard literature results; slightly smaller estimated fiscal multipliers.

The conditional variance decomposition shows that total factor productivity is the main driver of output variations and that it accounts for a significant percentage of the inflation variability in the long run. Price mark-up shocks play a significant role in explaining price inflation and output in the short run.

The rest of the paper is organized as follows. In the next section, we provide an overview of IGEM. ${ }^{2}$ Section 3 presents our results. Section 4 concludes.

\section{Model overview}

The core of IGEM is represented by the formalization of a segmented labor market. There are four categories of workers: skilled and unskilled employees, atypical workers, and self-employed workers. Workers of each category can be organized into unions to bargain their wages. Households are grouped into two types. 1) Ricardian households accumulate physical capital and (domestic and foreign) financial assets. Therefore, they can smooth their consumption. 2) Non-Ricardian households can

\footnotetext{
${ }^{2}$ The model is described in Appendix $\mathrm{A}$ in detail. All the estimated model equations are reported in Appendix B. The equations are fully derived in Annicchiarico et al. (2013b).
} 
not trade in financial markets or accumulate capital; they simply consume their after-tax disposable income. ${ }^{3}$ The heterogeneity of the households is linked to the labor market: Ricardian households supply labor services as employees (skilled and unskilled) and self-employed, while Non-Ricardian consumers provide labor services as atypical workers and unskilled employees.

Households can be either Ricardians or Non-Ricardians, $i \in\{R, N\}$. All of them consume the final non-tradable goods, $C_{t}$, and supply labor, $L_{t}$, receiving a nominal wage for each kind of labor input $j \in \ell$ according to the share supplied, $s_{j}$, to maximize:

$$
E_{0} \sum_{t=0}^{\infty} \beta^{t}\left[Z_{t} \log \left(C_{t}^{i}-h C_{t-1}\right)+\sum_{j \in \ell} \frac{\omega_{j}}{1-v_{j}} s_{j}^{i}\left(1-L_{j, t}^{i}\right)^{1-v_{j}}\right]
$$

where $\beta \in(0,1)$ is the subjective discount factor. Preferences display the external habit formation in consumption ( $h \in[0,1)$ is the habit coefficient); $Z_{t}$ is a consumption preference shock. The term $s_{j}^{i}$ denotes the share of household members who are able to work in the $j$ activity.

In the segmented labor market, the monopoly unions establish wages of skilled and unskilled workers, who exhibit stable contracts and strong protection. Therefore, employees are price makers; however, they face both price (nominal wages) and quantity (hiring and firing) adjustment costs. Self-employed workers and professionals supply labor under contracts for services; therefore, they also have market power due to the existence of professional orders or their limited number. Like skilled and unskilled workers, they face price and quantity adjustment costs.

The market power of skilled, unskilled, and self-employed workers introduces a wedge between the real wage and the marginal rate of substitution of consumption for leisure. Atypical workers have no market power; in their case, there is no wedge. These workers provide labor services taking the real wage as given. As price takers, their wage is flexible and they do not face adjustment costs.

Firms operate in four sectors that produce: tradable-intermediate goods, export goods, import goods, and final-consumption goods. Monopolistically competitive firms produce single tradable differentiated intermediate goods, $Y$, by using labor

\footnotetext{
${ }^{3}$ Among others, the relevance of liquidity constraints as an additional market imperfection has been highlighted by Gali et al. (2007), Di Bartolomeo and Rossi (2007), Coenen and Straub (2005), Forni et al. (2009), Di Bartolomeo et al. (2011), Albonico et al. (2017), and Ferrara and Tirelli (2017).
} 
and physical capital as inputs in the following production function:

$$
Y_{t}=A_{t}\left[\left(e^{\mu_{t}^{L}} N_{t}^{H L}\right)^{\alpha_{L}}\left(e^{\mu_{t}^{L}} N_{t}^{S A}\right)^{\alpha_{N}}\left(u_{t} K_{t}\right)^{1-\alpha_{L}-\alpha_{N}}\right]^{1-\alpha_{G}}\left(G_{t}^{K}\right)^{\alpha_{G}}
$$

where $A_{t}$ denotes the total factor productivity, ${ }^{4} N_{t}^{H L}$ and $N_{t}^{S A}$ denote CES aggregates of labor inputs hired $\left(N_{t}^{H L}\right.$ is a combination of skilled and unskilled labor inputs, $\mu_{t}^{L}$ is a specific labor-intensity shock; $u_{t}$ denotes the capital utilization rate; $N_{t}^{S A}$ includes labor inputs from self-employed and atypical workers); and $G_{t}^{K}$ is the stock of government capital whose level depends on investment decisions on public infrastructure. In changing labor inputs, firms are subject to convex adjustment costs.

In the export (import) sector, monopolistically competitive firms transform domestic (foreign) intermediate goods into exportable (importable) goods using a linear technology. The final goods are produced by combining a bundle of intermediate goods produced domestically with a bundle of imported intermediate goods according to a CES technology. Non-tradable final goods produced by the competitive firms can be used for private and public consumption and for private and public investment.

Several adjustment costs on nominal and real variables are modeled. These variables are assumed to be quadratic in the deviations from the steady state values and measured by a parameter $\gamma$ that captures their relevance. ${ }^{5}$

Specifically, the model features two kinds of nominal frictions (convex costs on price, measured by $\gamma_{p}$, and wage adjustments, measured by $\gamma_{\ell}^{W}$ ). The price adjustment equation is:

$$
\gamma_{p} \Omega_{t}\left(\Omega_{t}-1\right)=\gamma_{p} E_{t} \frac{\beta \varrho_{t+1}^{i}\left(\Omega_{t+1}-1\right) \Omega_{t+1} Y_{t+1}}{Y_{t}}+1-\theta_{Y}\left(1-\mathcal{M}_{t} M C_{t}\right)
$$

where $\Omega_{t}=\Pi_{t} /\left(\Pi_{t-1}^{\kappa_{p}} \bar{\Pi}^{1-\kappa_{p}}\right) ; \varrho_{t+1}^{i}$ represents the appropriate growth rate of the marginal utility of consumption/output; $\kappa_{P}$ measures price indexation; $\theta_{Y}$ is a measure of firms' market power; and $\mathcal{M}_{t}$ defines a markup shock.

Similarly, adjustments of wage of kind $i$ (which can be either skilled, unskilled

\footnotetext{
${ }^{4}$ It evolves according to an $A R(1)$ process in logs.

${ }^{5}$ For instance, for a variable $X_{t}$, the adjustment cost is $\gamma\left(X_{t}-\bar{X}\right)^{2} X_{t} / 2$.
} 
workers or self-employed) are described by

$$
\frac{\gamma_{S}^{W} \Omega_{t}^{i}\left(\Omega_{t}^{i}-1\right) Y_{t}}{\left(\sigma_{i}-1\right) L_{S, t}}=\gamma_{i}^{W} E_{t} \frac{\beta \varrho_{t+1}^{i} \Omega_{t+1}^{i}\left(\Omega_{t+1}^{i}-1\right) Y_{t+1}}{\left(\sigma_{i}-1\right) L_{i, t}}+\mathcal{M}_{t}^{i} \frac{\sigma_{i} M R S_{t}^{i}}{\sigma_{i}-1}-W R T_{t}^{i}
$$

where $\Omega_{t}^{i}=\Pi_{t} W R_{t}^{i} /\left(W R_{t-1}^{i} \Pi_{t-1}^{\kappa_{W}} \bar{\Pi}^{1-\kappa_{W}}\right), W R^{i}$ is the real wage and $\kappa_{W}$ measures price indexation; $W R T^{i}$ is the post-tax real wage of workers of kind $i$ and $M R S^{i}$ is their marginal rate of substitution between labor and consumption; $\sigma_{i}$ is the elasticity of substitution between workers of kind $i ; \mathcal{M}_{t}^{i}$ is a wage-markup shock for skilled and unskilled workers.

In the model there are five sources of real rigidities (investment, $\gamma_{I}$, and labor adjustment $\operatorname{costs} \gamma_{\ell}^{L}$, variable capital utilization, external habit in consumption, and imperfect competition in product and labor markets). Regarding the investment, Ricardians own physical capital and control the rate of capital utilization. Physical capital accumulates according to:

$$
K_{t+1}=\left(1-\delta_{K}\right) K_{t}+I_{t}
$$

where $\delta_{K}$ denotes the depreciation rate of physical capital. Investment decisions are subject to a convex adjustment cost measured by $\exp \left(\mu_{t}^{I}\right) \gamma_{I}$, where $\mu_{t}^{I}$ is a stochastic disturbance.

A foreign sector and monetary and fiscal authorities adopting rule-based stabilization policies are exogenously assumed.

The government issues nominal debt in the form of interest-bearing bonds. Public consumption and investment, interest payments on outstanding public debt, transfers to households and subsidies to firms are financed by taxes on capital, labor and consumption and/or by issuance of new bonds. To ensure that the fiscal budget constraint is met, the fiscal authority is assumed to adopt a fiscal rule responding to public debt. Public consumption evolves according to $A R(1)$ processes in log deviations from its steady state. The tax dynamics are described by a fiscal rule, which captures the tax response to the public finance indicators (debt and deficit) and the stance of stabilization policies.

The external monetary authority (ECB) controls the nominal interest rate $\left(R_{t}\right)$, which responds to some extent to domestic conditions. Specifically, the monetary authority adopts a Taylor-type interest rate rule, reacting to inflation $\left(\Pi_{t}\right)$ and output $\left(Y_{t}\right)$, augmented by past nominal interest rate (smoothing its effects) and 
nominal exchange rate $\left(S_{t}\right)$ deviations from the long-run value. Formally, we model monetary policy as

$$
\frac{R_{t}}{\bar{R}}=\left(\frac{R_{t-1}}{\bar{R}}\right)^{\iota_{r}}\left[\left(\frac{\Pi_{t}}{\bar{\Pi}}\right)^{\iota_{\pi}}\left(\frac{Y_{t}}{\bar{Y}}\right)^{\iota_{y}}\left(\frac{S_{t}}{\bar{S}}\right)^{\iota_{s}}\right]^{1-\iota_{r}} e^{u_{t}^{R}}
$$

where $\bar{R}$ is the equilibrium nominal interest rate, $\bar{\Pi}$ is the monetary authority inflation target, $\bar{Y}$ is the steady state output, $\bar{S}$ is the long-run (steady state) exchange rate; $\iota_{R}, \iota_{\Pi}, \iota_{Y}, \iota_{S}$ are policy parameters; and $u_{t}^{R}$ is an $A R(1)$ stochastic disturbance, capturing the effects of innovations in monetary policy.

The foreign sector is modeled as exogenous. The development of the net foreign asset position depends on the current account surplus and thus on the decisions of firms, households and government. The transmission mechanism from internal to external variables is further complicated by the assumption that the domestic exporting and importing firms have market power in the prices they set, such that the net external position will depend on conditions in both financial and goods markets. ${ }^{6}$

\section{Estimation}

In this section we provide the estimation with Bayesian techniques of the linearized version of IGEM. The priors are fully specified, and the estimates hinge on prior assumption about the range of admissible values. Bayesian estimation relies on the well-known Bayes' rule:

$$
p\left(\theta \mid Y_{T}\right)=\frac{p(\theta) p\left(Y_{T} \mid \theta\right)}{p\left(Y_{T}\right)}
$$

where $p(\theta)$ is the prior assigned to parameter $\theta, p\left(Y_{T} \mid \theta\right)$ is the likelihood and $p\left(\theta \mid Y_{T}\right)$ is the posterior density. Formally, the prior distribution and the likelihood function are combined to obtain the posterior distribution; however, in complex problems, this is typically not available in closed form and simulation strategies, such as the Markov Chain Monte Carlo, are necessary. Here we have used the well-known Metropolis-Hastings algorithm. ${ }^{7}$

The model is estimated using various macroeconomic data for the Italian econ-

\footnotetext{
${ }^{6}$ See Schmitt-Grohé and Uribe (2003).

${ }^{7}$ For a wider discussion on Bayesian methods applied to DSGE estimation, see An and Schorfheide (2007) and Fernández-Villaverde (2010).
} 
omy. In particular, we use quarterly data ranging from 1992:1 - 2012:4. Nine variables are used as observables: real GDP, real consumption, real investment, inflation, nominal interest rate, real wage and hours of skilled and unskilled workers. The series describing wages and hours worked come from the INPS database, while the other series are taken from EUROSTAT. The band-pass filter was used to detrend the series. To avoid stochastic singularity, we estimate a set of shocks equal to the number of observable variables. The following shocks are considered: total factor productivity $\left(\varepsilon_{t}^{T F P}\right)$, public consumption $\left(\varepsilon_{t}^{G}\right)$, monetary policy $\left(\varepsilon_{t}^{R}\right)$, preference $\left(\varepsilon_{t}^{z}\right)$, investment specific $\left(\varepsilon_{t}^{I}\right)$, price mark-up $\left(\varepsilon_{t}^{\mu}\right)$, wage mark-up high-skilled $\left(\varepsilon_{t}^{w_{l h}}\right)$, wage mark-up unskilled $\left(\varepsilon_{t}^{w_{l l}}\right)$, and labor intensity $\left(\varepsilon_{t}^{L}\right)$.

To avoid the correlation between observables and to improve the fit of the model, we allow for three measurement errors for the following observables: output gap, high-skilled hours, and unskilled hours. All the shocks follow an $A R(1)$ stationary process, while the shock of monetary policy and measurement errors are based on a white noise process. We have selected the subset of parameters to be estimated based on the identification test proposed by Iskrev (2010). The subset of parameters that we estimate is mainly composed of parameters that influence the dynamics of the model, such as adjustment costs and nominal rigidities.

Before estimating, we performed a global sensitivity analysis test to investigate which regions of the prior support could potentially drive the indeterminacy/instability of the model. ${ }^{8}$ From the test, we have obtained that all parameter values in the specified intervals provide a unique saddle-path solution.

The remaining parameters of the model have been calibrated as in Annicchiarico et al. (2013a). Specifically, IGEM is calibrated on a quarterly basis to match steadystate ratios and specific features of the Italian economy. With regard to the main ratios, the private consumption share $C / Y$ is 0.57 , the investment share $I / Y$ is 0.18 , the public consumption share $G / Y$ is $0.20 .^{9}$

Table 1 reports the description of each estimated parameter.

\footnotetext{
${ }^{8}$ The test is implemented using the GSA toolbox in Dynare.

${ }^{9}$ See Appendix C for a brief discussion on IGEM calibration.
} 
Table 1 - Estimated parameters description

\begin{tabular}{ll}
\hline \hline Parameter & Description \\
\hline$\gamma_{p}$ & Price adjustment cost \\
$\kappa_{p}$ & Price indexation \\
$\gamma_{S}^{W}$ & Wage adjustment cost self-employed workers \\
$\gamma_{H}^{W}$ & Wage adjustment cost high-skilled workers \\
$\gamma_{L}^{W}$ & Wage adjustment cost unskilled workers \\
$\gamma_{S}^{L}$ & Labor adjustment cost self-employed workers \\
$\gamma_{H}^{L}$ & Labor adjustment cost high-skilled workers \\
$\gamma_{L}^{L}$ & Labor adjustment cost unskilled workers \\
$\gamma_{A}^{L}$ & Labor adjustment cost atypical workers \\
$\kappa_{W}$ & Wage indexation \\
$\gamma_{I}$ & Investment adjustment cost \\
$\iota_{r}$ & Taylor rule parameter, interest \\
$\iota_{\pi}$ & Taylor rule parameter, inflation \\
$\iota_{y}$ & Taylor rule parameter, output \\
$\iota_{s}$ & Taylor rule parameter, exchange rate \\
$\rho_{u^{R}}$ & AR(1) coefficient monetary policy shock \\
$\rho_{\mu^{w}}^{H}$ & AR(1) coefficient wage mark-up shock (high-skilled) \\
$\rho_{\mu^{w}}^{L}$ & AR(1) coefficient wage mark-up shock (unskilled) \\
$\rho_{I}$ & AR(1) coefficient investment specific shock \\
$\rho_{L}$ & AR(1) coefficient labor intensity shock \\
$\rho_{G}$ & AR(1) coefficient public spending shock \\
$\rho_{T F P}$ & AR(1) coefficient TFP shock \\
$\rho_{Z}$ & \\
$\rho_{\mu}$ & \\
\hline \hline & AR(1) coefficient preference shock \\
\hline
\end{tabular}

Prior distributions are centered on a mean equal to the calibrated value in IGEM for the correspondent parameter; we choose a Beta distribution for all the parameters with support [0,1], a Gamma distribution for the remaining parameters, whereas an Inverse Gamma distribution is used for the variances of the shocks.

Posterior distributions are obtained by the Metropolis-Hastings algorithm; the procedure is implemented using the Matlab-based Dynare package. Mean and posterior percentiles come from two chains of 50,000 draws each from Metropolis- 
Hastings algorithm, where we discarded the initial 30\% draws.

Table 2 provides the result of our estimation for the parameters characterizing the model, with the posterior mean and median estimates at the $90 \%$ credible intervals.

Table 2 - Prior and posterior distributions (model parameters)

\begin{tabular}{ccccccccc}
\hline \hline & \multicolumn{3}{c}{ Prior distribution } & & \multicolumn{4}{c}{ Posterior distribution } \\
\cline { 2 - 3 } \cline { 8 - 9 }$\iota_{r}$ & Density & Mean & S.D. & & Mean & Median & $10 \%$ & $90 \%$ \\
$\iota_{\pi}$ & Beta & 0.750 & 0.100 & & 0.851 & 0.850 & 0.819 & 0.885 \\
$\iota_{y}$ & Normal & 1.500 & 0.250 & & 1.376 & 1.306 & 1.133 & 1.634 \\
$\iota_{s}$ & Normal & 0.125 & 0.050 & & 0.225 & 0.229 & 0.147 & 0.302 \\
$\gamma_{S}^{W}$ & Normal & 0.010 & 0.005 & & 0.012 & 0.012 & 0.006 & 0.019 \\
$\gamma_{H}^{W}$ & Gamma & 10 & 3 & & 8.843 & 10.466 & 4.883 & 12.780 \\
$\gamma_{L}^{W}$ & Gamma & 71 & 15 & & 32.552 & 45.305 & 17.355 & 47.583 \\
$\gamma_{S}^{L}$ & Gamma & 71 & 15 & & 48.608 & 55.303 & 29.327 & 66.848 \\
$\gamma_{H}^{L}$ & Gamma & 15 & 5 & & 0.880 & 0.630 & 0.553 & 1.224 \\
$\gamma_{L}^{L}$ & Gamma & 15 & 5 & & 20.735 & 19.703 & 15.900 & 25.074 \\
$\gamma_{A}^{L}$ & Gamma & 15 & 5 & & 49.640 & 45.550 & 37.958 & 60.542 \\
$\kappa_{W}$ & Beta & 0.500 & 0.150 & & 0.106 & 0.084 & 0.036 & 0.175 \\
$\gamma_{p}$ & Gamma & 330 & 50 & & 309.400 & 314.202 & 235.582 & 387.795 \\
$\kappa_{p}$ & Beta & 0.500 & 0.150 & & 0.121 & 0.105 & 0.041 & 0.198 \\
$\gamma_{I}$ & Gamma & 75 & 25.00 & 112.657 & 96.351 & 73.432 & 151.860 \\
\hline \hline
\end{tabular}

In Table 3, we report the estimated standard deviation of the shocks considered and their autocorrelation parameters. For the standard deviations, we have elicited an Inverse Gamma distribution with 2 degrees of freedom, while all the $A R(1)$ follow a Beta distribution. As in Table 2, we report posterior mean, posterior median and the $90 \%$ credible interval. 
Table 3 - Prior and posterior distributions (shocks, s.d., and $A R(1)$ coefficients)

\begin{tabular}{|c|c|c|c|c|c|c|c|}
\hline & \multicolumn{3}{|c|}{ Prior distribution } & \multicolumn{4}{|c|}{ Posterior distribution } \\
\hline & Density & Mean & S.D. ${ }^{10}$ & Mean & Median & $10 \%$ & $90 \%$ \\
\hline$\varepsilon_{t}^{T F P}$ & Inv. Gamma & 0.01 & 2 & 0.010 & 0.001 & 0.008 & 0.012 \\
\hline$\varepsilon_{t}^{G}$ & Inv. Gamma & 0.01 & 2 & 0.019 & 0.018 & 0.016 & 0.022 \\
\hline$\varepsilon_{t}^{R}$ & Inv. Gamma & 0.01 & 2 & 0.002 & 0.002 & 0.001 & 0.002 \\
\hline$\varepsilon_{t}^{z}$ & Inv. Gamma & 0.01 & 2 & 0.009 & 0.009 & 0.008 & 0.011 \\
\hline$\varepsilon_{t}^{\mu}$ & Inv. Gamma & 0.01 & 2 & 2.041 & 2.045 & 1.457 & 2.587 \\
\hline$\varepsilon_{t}^{w_{l h}}$ & Inv. Gamma & 0.01 & 2 & 0.649 & 0.853 & 0.310 & 0.954 \\
\hline$\varepsilon_{t}^{w_{l l}}$ & Inv. Gamma & 0.01 & 2 & 1.271 & 1.410 & 0.719 & 1.816 \\
\hline$\varepsilon_{t}^{L}$ & Inv. Gamma & 0.01 & 2 & 0.010 & 0.010 & 0.009 & 0.011 \\
\hline$\varepsilon_{t}^{I}$ & Inv. Gamma & 0.01 & 2 & 0.004 & 0.003 & 0.002 & 0.005 \\
\hline$\rho_{G}$ & Beta & 0.5 & 0.1 & 0.780 & 0.796 & 0.676 & 0.877 \\
\hline$\rho_{T F P}$ & Beta & 0.5 & 0.1 & 0.953 & 0.953 & 0.935 & 0.971 \\
\hline$\rho_{Z}$ & Beta & 0.5 & 0.1 & 0.625 & 0.622 & 0.481 & 0.776 \\
\hline$\rho^{I}$ & Beta & 0.5 & 0.1 & 0.853 & 0.865 & 0.813 & 0.897 \\
\hline$\rho_{\mu}$ & Beta & 0.5 & 0.1 & 0.119 & 0.108 & 0.022 & 0.205 \\
\hline$\rho_{\mu^{w}}^{H}$ & Beta & 0.5 & 0.1 & 0.228 & 0.228 & 0.094 & 0.342 \\
\hline$\rho_{\mu^{w}}^{L}$ & Beta & 0.5 & 0.1 & 0.214 & 0.210 & 0.075 & 0.352 \\
\hline$\rho_{L}$ & Beta & 0.5 & 0.1 & 0.574 & 0.583 & 0.375 & 0.768 \\
\hline$\rho_{u^{R}}$ & Beta & 0.5 & 0.1 & 0.071 & 0.058 & 0.014 & 0.123 \\
\hline
\end{tabular}

From the estimate, we observe a high degree of persistence for the interest rate, which is in line with the literature. The costs of adjustment of prices and wages indicate a considerable degree of nominal rigidity in the economy. As expected, when considering shocks, the total factor productivity has a high degree of autocorrelation, which indicates a high degree of inertia, while mark-up shocks appear to be less persistent.

In the labor market, the estimated adjustment costs of prices (nominal wages) and quantities (hiring and firing costs) are relevant for employees, especially for low skilled workers, who suffer high hiring and firing costs. Moderate price and quantity adjustment costs are estimated for the self-employed; their hiring and firing costs are lower than those of atypical workers.

The estimated wage rigidities are usually lower than their correspondent values

\footnotetext{
${ }^{10}$ For the Inverse Gamma distribution, the degrees of freedom are indicated.
} 
in the calibrated IGEM, while the opposite is true for the adjustment costs of quantities. The same applies to the adjustment costs of investments. Finally, a moderate indexation of prices and wages is observed (lower than the value assumed in the IGEM calibration).

In the figures below, we represent the prior (gray line) and posterior (black line) distribution of the estimated parameters. The green line indicates the mode. We observe that, for all the parameters, the posterior shape is well formed and does not overlap with the prior distribution, showing that all the estimated parameters are correctly identified. In Appendix D, we provide further details to verify the robustness of our estimates.
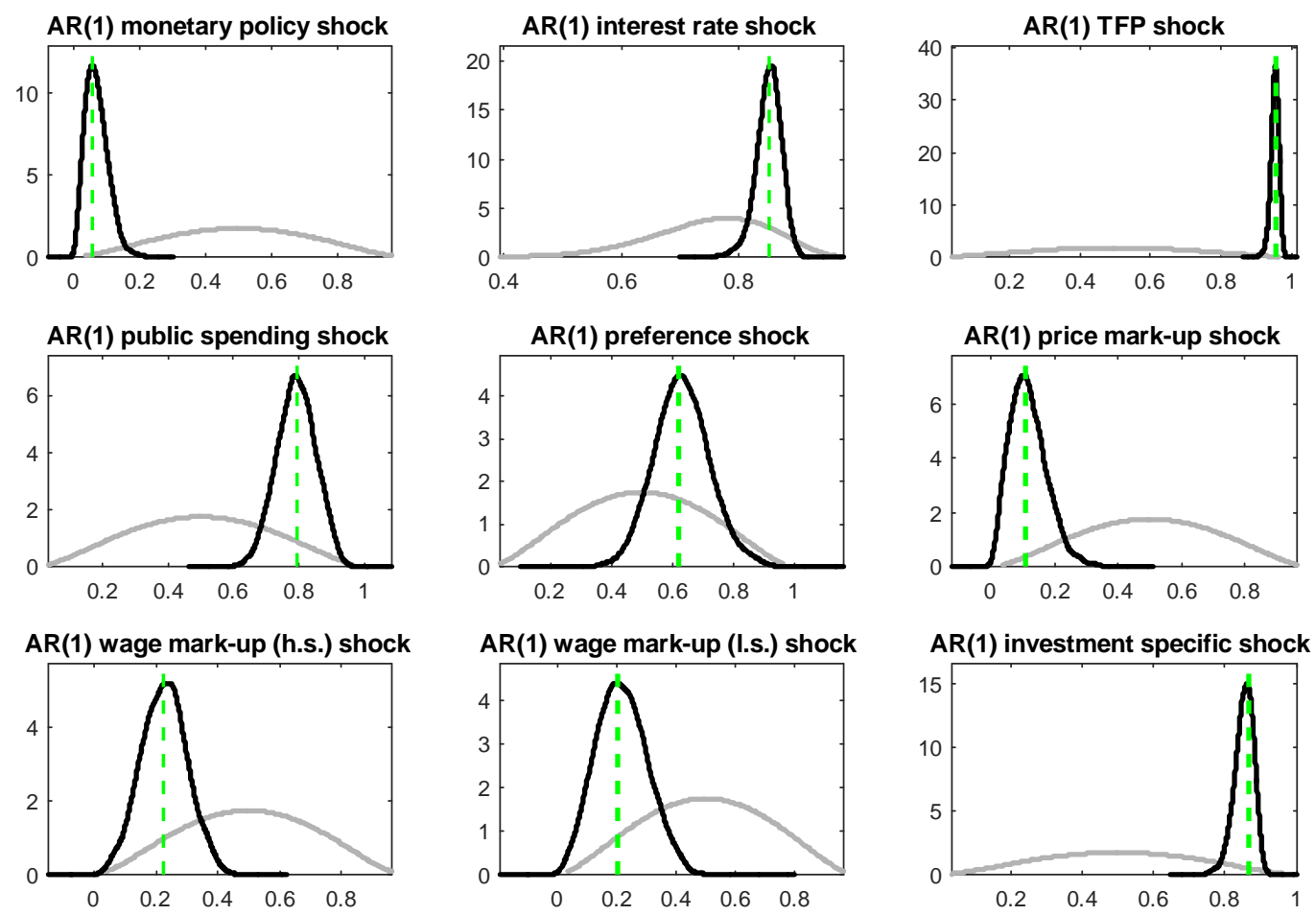

Figure 1 - Prior and posterior distributions 

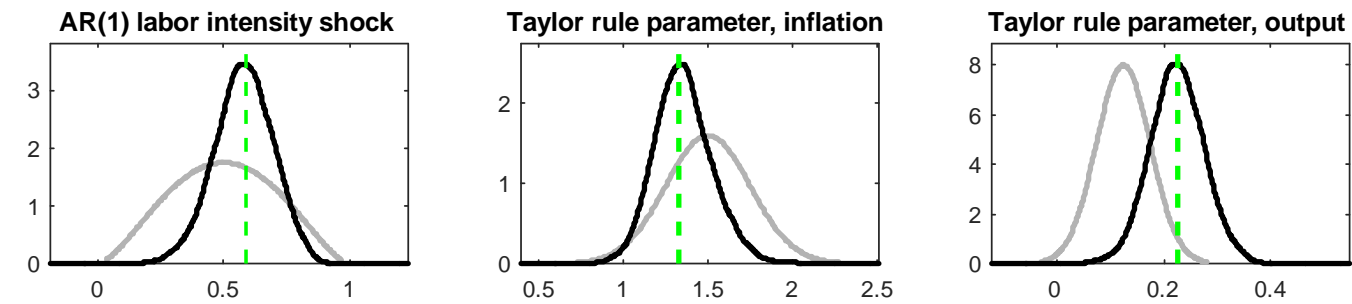

Taylor rule parameter, exchange rate
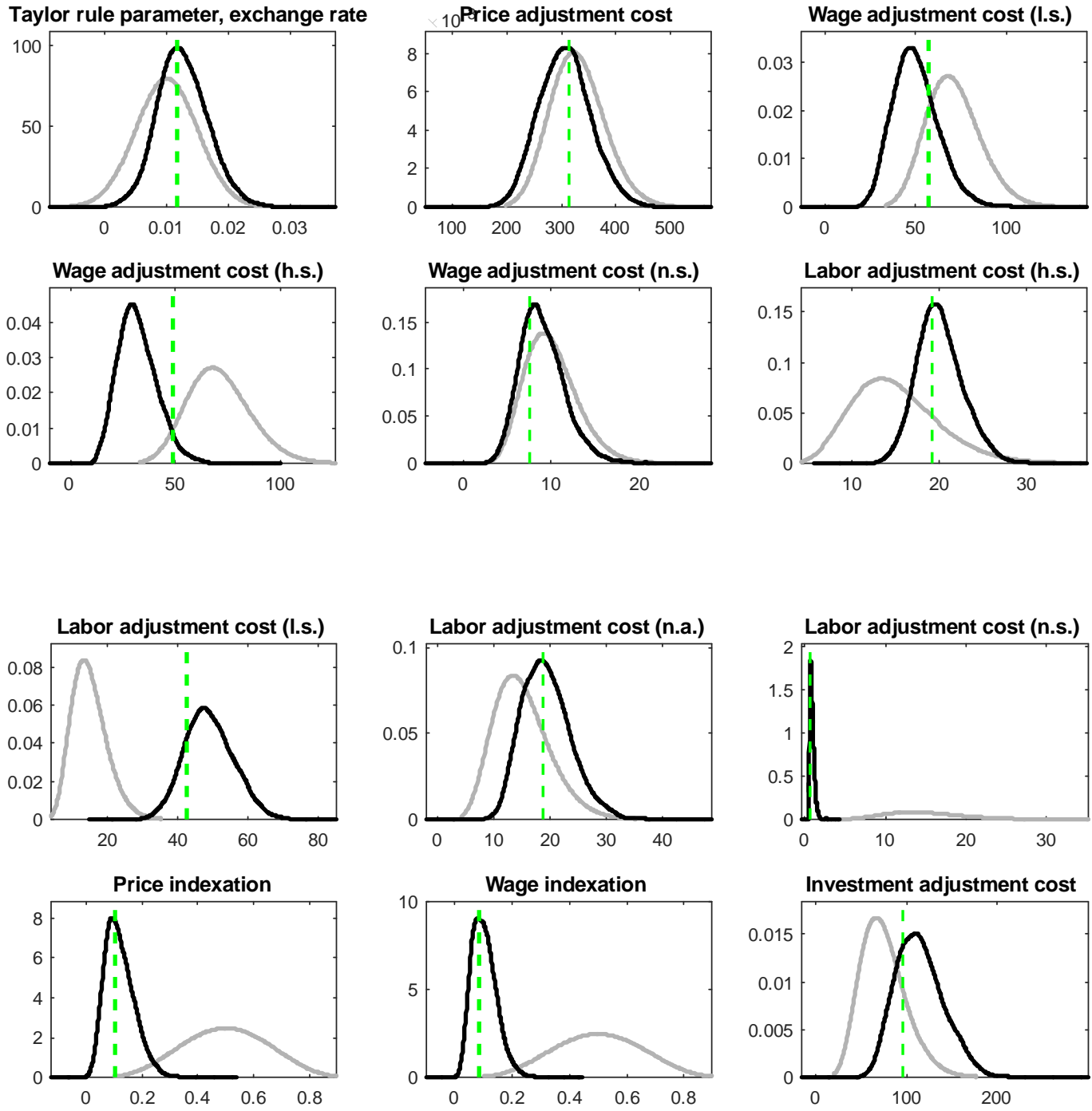

Figure 2 - Prior and posterior distributions 


\subsection{Impulse response analysis}

This section presents a simulation of the effects on the Italian economy of structural shocks for a set of selected endogenous variables. We assess the IRFs to the structural shocks whose magnitude and autocorrelation originate from their posterior estimated mean. Specifically, we consider the dynamic mean response of output, consumption, nominal interest rate, inflation, investment, hours worked and real wage for both high-skilled and unskilled to three structural shocks, total factor productivity, public consumption, and monetary policy. The IRFs are depicted in the next figures, where the black line is the mean IRF, and the gray-shaded areas provide the highest posterior density intervals at $90 \%$ of confidence.
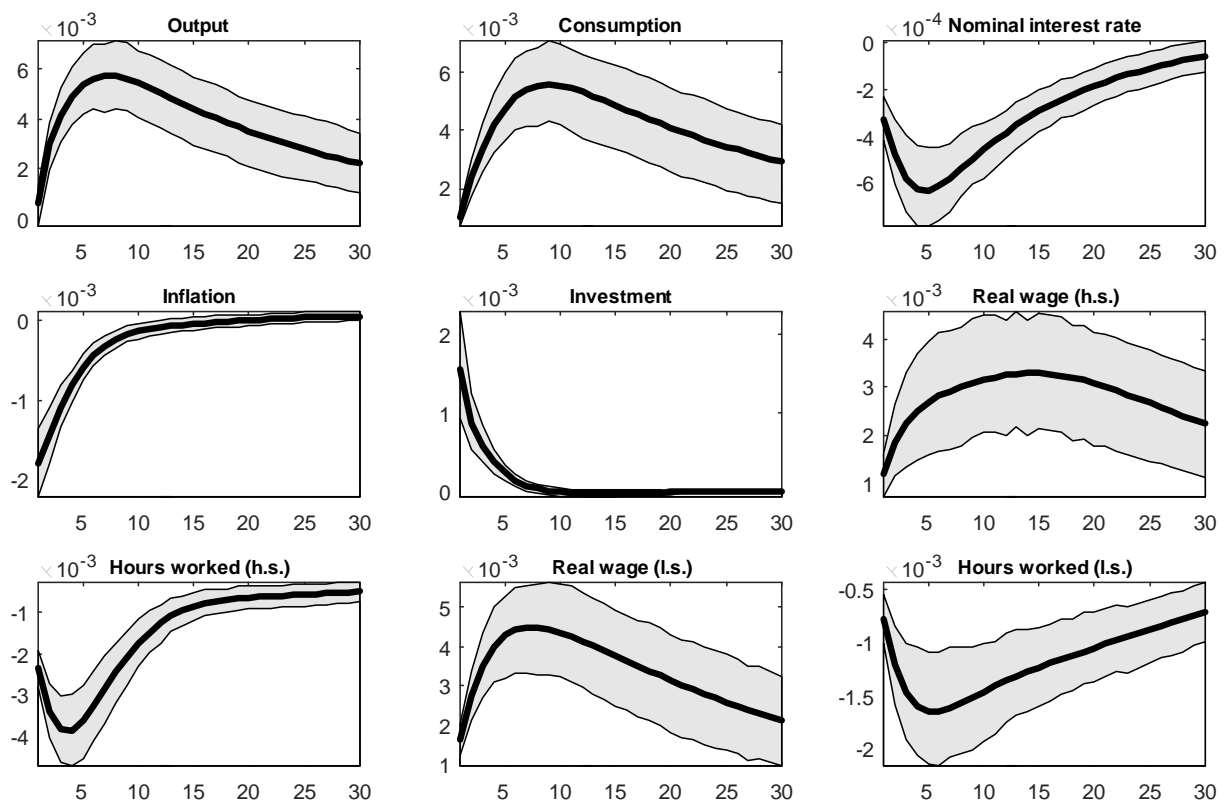

Figure 3 - Impulse response function to a TFP shock

In Figure 3, we show the dynamic response to a TFP shock. As expected, an improvement in the total factor productivity has positive effects on output, consumption, and investment. The real wage also rises; however, there is a negative employment effect. Labor initially decreases and then progressively returns to its steady state. Supply shocks lead to a demand externality due the presence of nominal rigidities (Galí, 1999). Specifically, after the positive shock in total factor productivity, firms are able to produce more for a given level of input. In the early periods after the shock, aggregate demand does not adjust immediately due to price 
stickiness; thus, firms reduce the number of hours worked.
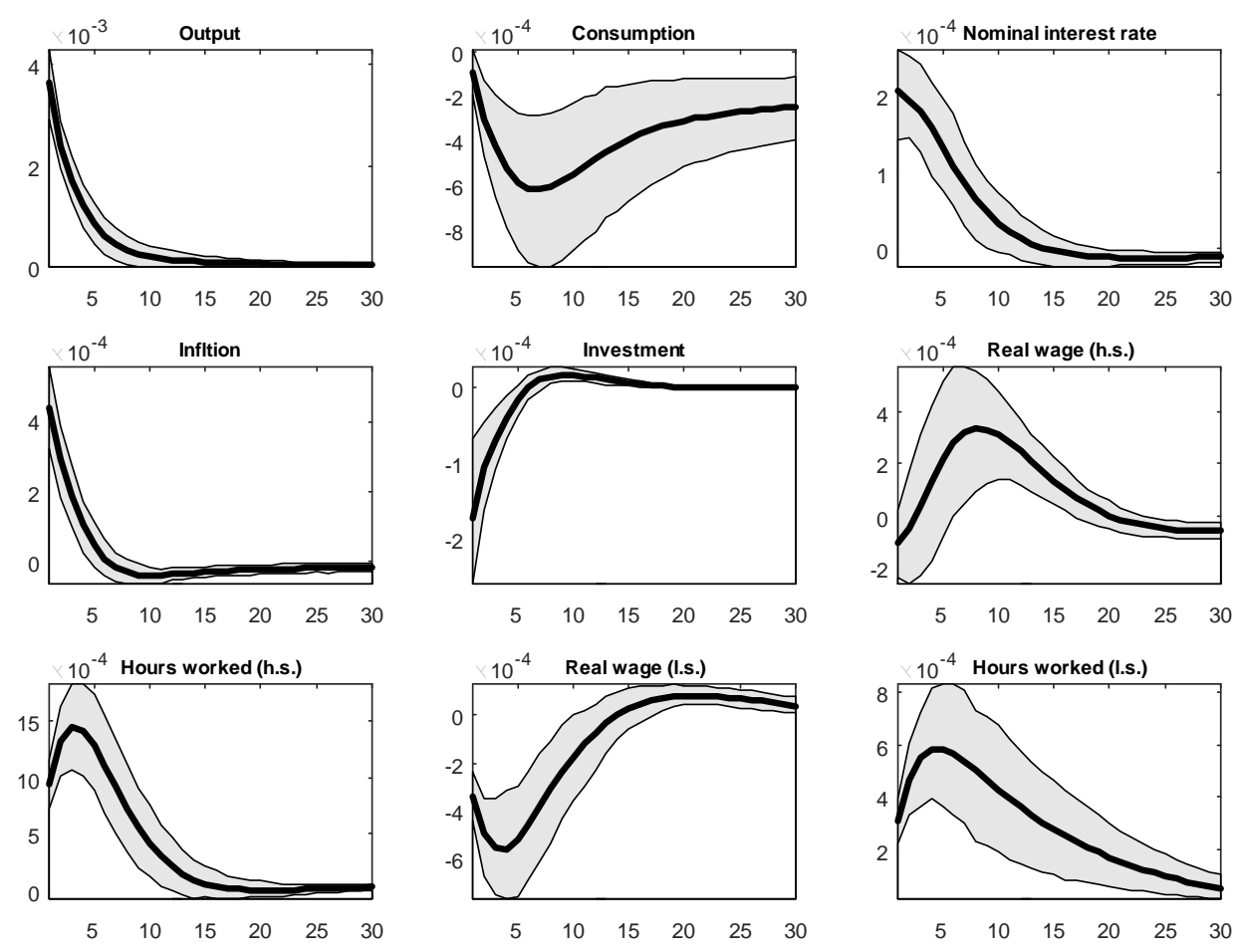

Figure 4 - Impulse response function to a public consumption shock

The IRFs to a positive shock in the government spending are plotted in Figure 4. Output and labor exhibit an initial increase, whereas higher public spending crowds out private consumption and investment. Although there is a significant level of liquidity constrained consumers, a positive shock on public consumption entails a fall in the aggregate level of consumption. The same result is found in QUEST III (D'Auria et al., 2009). 

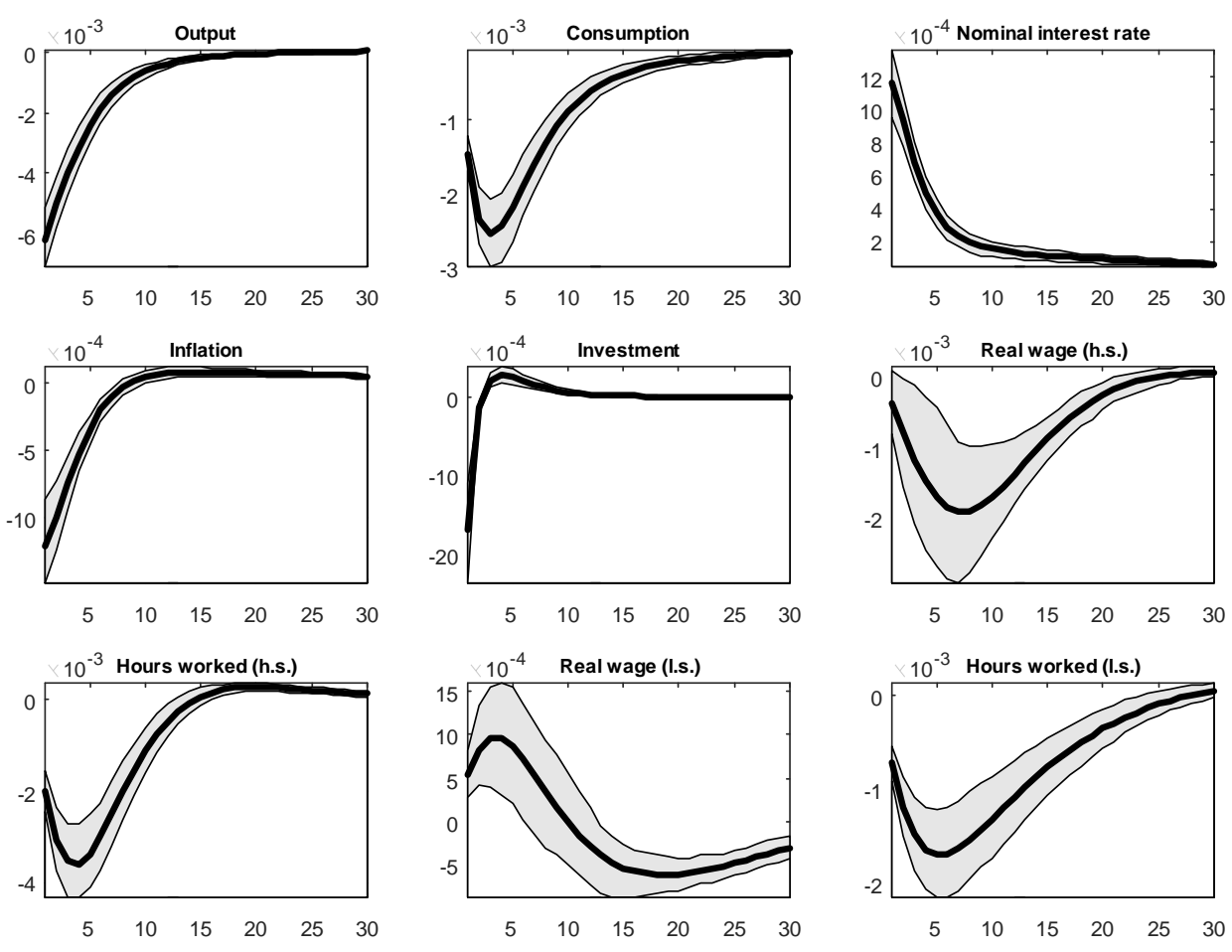

Figure 5 - Impulse response function to a monetary policy shock

In Figure 5, we show the dynamics of the selected variables when a monetary tightening is considered. The policy innovation leads to a rise in the nominal shortterm interest rate. As the monetary tightening involves a fall in inflation, the real interest rate increases more than the nominal one. For each one-percent increase in inflation, the central bank tends to raise the nominal interest rate by more than one percentage point. A monetary tightening then involves a reduction in consumption and investment and entails a decrease of the output. Hours worked decrease for both high-skilled and unskilled workers.

Figure 5 does not imply a hump-shaped path for output after an innovation in monetary policy, although this path is clearly observed for consumption. The rationale lies in the open-economy nature of the model. In fact, the increase in the interest rate on public debt, given the foreign one, stimulates a quick appreciation in the domestic currency due to arbitrage. The resulting fall in competitiveness leads to a strong increase in imports and a fall of exports. The initial worsening of the current account (when the interest rate is higher) leads to a greater fall in domestic production, which adds to the initial (moderate) fall in consumption, be- 
cause of its hump-shaped pattern. As the interest rate returns to its initial value, the competitiveness also returns to its initial level, the effect of trade balance becomes moderate; however, consumption continues to decline until its negative peak is achieved. As consumption resumes and the negative current account disappears, the fall in output shrinks. Thus, no hump-shape is observed for the output path after a monetary shock.

Finally, we compute some short-run fiscal multipliers. As many papers emphasize how temporary fiscal policies can have different effects on output if monetary policy remains accommodative for a prolonged period, we assess the impact of various fiscal policies under alternative assumptions about the stance of monetary policy (accommodative and non-accommodative policies). ${ }^{11}$ Fiscal multipliers obtained from the estimated version of IGEM are compared to those stemming from the calibrated version. The one-year fiscal multiplier on real GDP is between 0.885 and 1.469, depending on the stance of monetary policy. The corresponding multiplier for the calibrated version of the model instead oscillates between 1.069 and 1.941. The public investment multiplier is between 1.024 and 1.501 (estimated IGEM) against 1.270 and 2.003 (calibrated IGEM). Finally, the one-year effects of a tax change on real GDP is between 0.397 and 0.805 . In the calibrated version of IGEM, it oscillates between 0.433 and 1.029 .

\subsection{Variance decomposition}

We analyze the contribution of each of the structural shocks to the forecast error variance of output and inflation at various horizons. In particular, by $t=4$ we indicate the short run (1 year); $t=10$ labels the medium run (2.5 years); and $t=100$ denotes the long run (25 years).

\footnotetext{
${ }^{11}$ Fiscal multipliers are computed by following Coenen et al. (2012).
} 
Table 4 - Variance decomposition

\begin{tabular}{c|cccccc}
\hline \hline \multirow{2}{*}{ Shock } & \multicolumn{2}{|c}{$t=4$} & \multicolumn{2}{c}{$t=10$} & \multicolumn{2}{c}{$t=100$} \\
& Output & Inflation & Output & Inflation & Output & Inflation \\
\hline TFP & 18.26 & 15.43 & 47.51 & 16.44 & 67.04 & 17.13 \\
Public spending & 8.59 & 0.67 & 5.06 & 0.66 & 3.15 & 0.68 \\
Monetary policy & 31.89 & 6.80 & 20.48 & 6.88 & 12.77 & 7.14 \\
Preference & 1.63 & 0.26 & 1.19 & 0.26 & 0.74 & 0.27 \\
Investment specific & 1.16 & 0.02 & 0.65 & 0.02 & 0.40 & 0.02 \\
Price mark-up & 38.24 & 76.74 & 24.59 & 75.60 & 15.27 & 74.59 \\
Wage mark-up (h.s.) & 0.00 & 0.01 & 0.01 & 0.02 & 0.01 & 0.02 \\
Wage mark-up (l.s.) & 0.23 & 0.07 & 0.51 & 0.12 & 0.63 & 0.15 \\
Labor intensity & 0.00 & 0.00 & 0.00 & 0.00 & 0.00 & 0.00 \\
\hline \hline
\end{tabular}

In the short run, changes in output are mainly determined by price mark-up, monetary and TFP shocks; public spending shocks also play an important role in explaining the variability of output. As the forecast horizon increases, the relative importance of the price mark-up shocks decreases, and disturbances in total factor productivity are able to roughly explain $3 / 4$ of output variability. With regard to inflation, there are two main determining factors: price mark-up and technological shocks. In the short run, the mark-up shock is the main driver of inflation variability. In the long run, the mark-up shock is still the main determinant of inflation volatility, but now the TFP shocks account for around $17 \%$ of its variation.

\subsection{Historical decomposition}

This section studies the historical contribution of each estimated shock to the output and inflation deviations from 2000 onwards (with particular attention to the recent crisis). The decomposition is based on the best estimates of the various shocks. Although historical decompositions should be treated with caution, they help in understanding how the estimated models interpret specific changes (for instance, recessions) in observed data.

The historical contribution of the various structural shocks to output and inflation are summarized in Figure 6 and 7. The black lines represent the deviation of the smoothed value of the endogenous variables (output or inflation) from their 
steady state. The colored bars correspond to the contribution of different shocks to those deviations. The initial values in the graphs refer to the portion of the steady state deviations that are explained by the unknown initial value of the state variables and not by the smoothed shocks. The influence of initial values usually extinguishes relatively quickly.

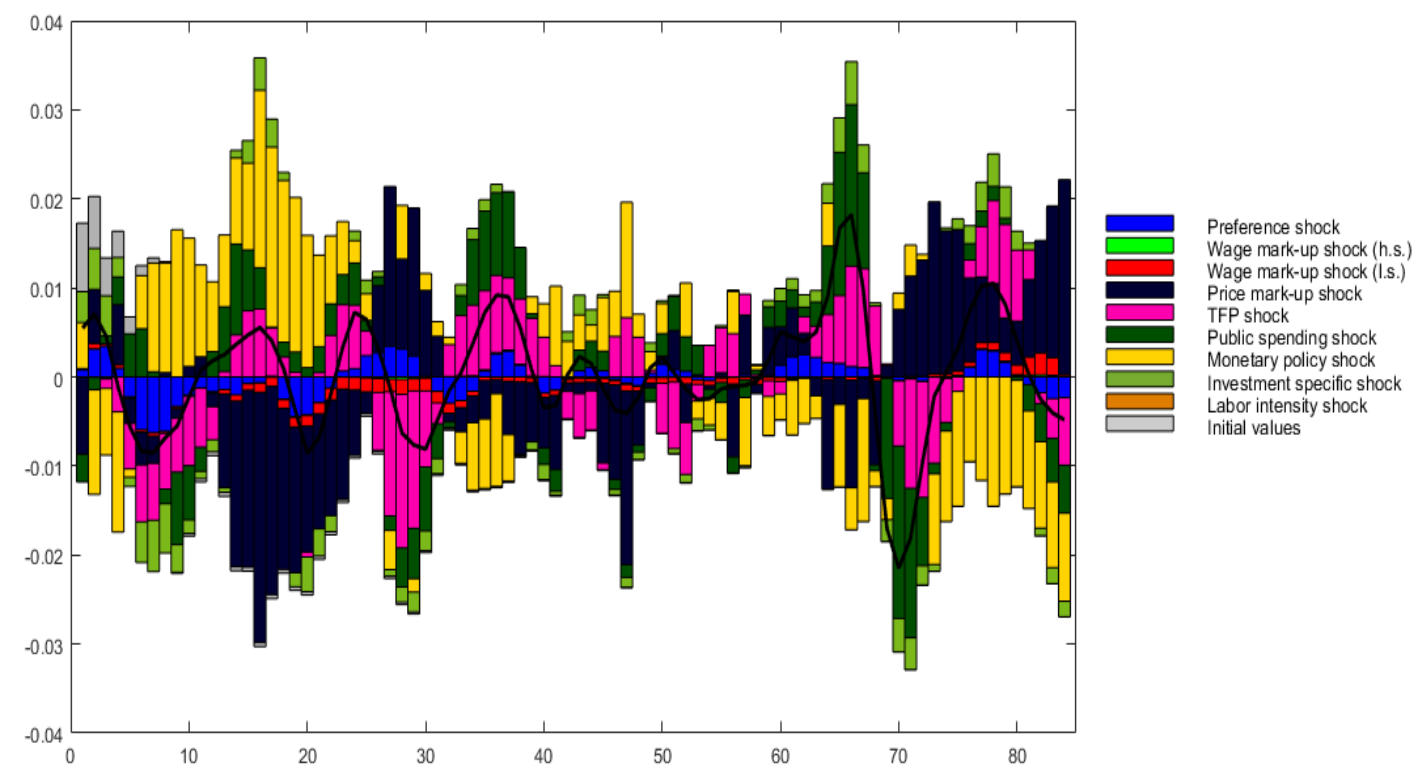

Figure 6 - Historical decomposition of output

Figure 6 describes the output gap decomposition. We observe that the recession in the early 1990s was mainly driven by adverse preference, risk premium and TFP shocks. Conversely, the recent crisis was driven by negative preference and public spending shocks. The former remained the main driver of the 2012 downturn. 


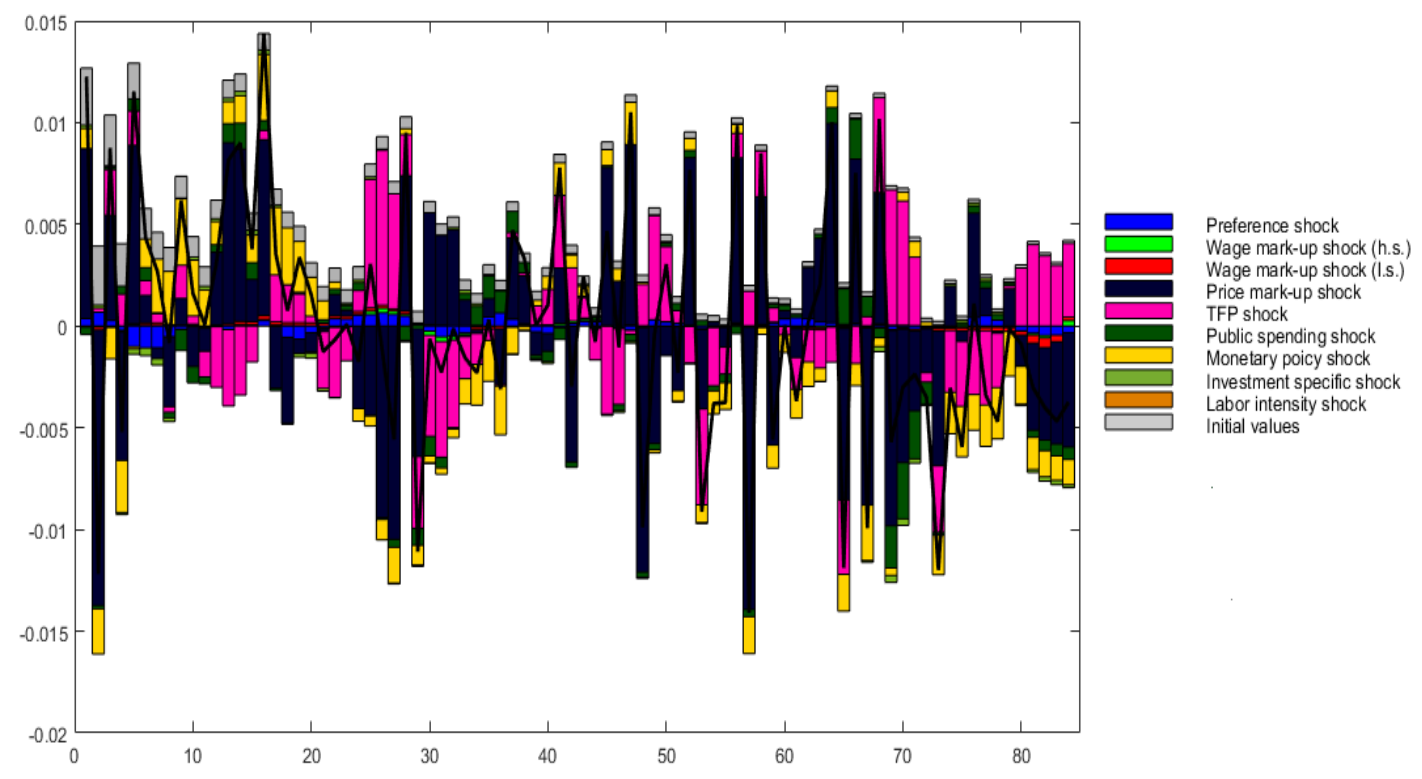

Figure 7 - Historical decomposition of inflation

Examining the historical decomposition of inflation (Figure 7), we find that price mark-up shock is strictly correlated with inflation movements along the entire sample. Inflationary episodes are mainly induced by a mark-up increase, and deflationary periods are associated with negative mark-up shocks. Monetary policy appears to have a negligible role in explaining the cyclical variation of inflation in the sample considered.

\section{Conclusions}

The small-open economy model of the Italian economy (IGEM) ${ }^{12}$ has been estimated with Bayesian techniques. We considered five macro-variables, namely GDP, consumption, investment, inflation, and nominal interest rate. Moreover, given the model's focus on the labor market, we also considered four additional variables measuring real wage and hours worked for high- and low-skilled workers. A wide set of well-identified parameters, concentrating on parameters affecting the dynamics of the model have been estimated.

Our empirical results can be summarized as follows.

1. Compared to the calibrated version of IGEM, estimated nominal wage stickiness is smaller for all types of work; by contrast, adjustment costs (including

\footnotetext{
${ }^{12}$ Originally developed by Annicchiarico et al. (2013a).
} 
those for investments) are higher. The degree of prices and wages indexation to past inflation is much smaller than the indexation levels assumed in the calibrated model. No substantial difference is found in the estimated monetary parameters. Estimated fiscal multipliers are slightly smaller than those obtained from the calibrated model.

2. Closely examining the segmented labor market, the IGEM core, both nominal wages and hiring/firing costs are relevant for employees - particularly for those who are low skilled. By contrast, the estimated price and quantity adjustment costs are moderate for the self-employed. Finally, atypical workers are subject to relevant hiring and firing costs.

3. The disturbances of total factor productivity exhibit a high degree of inertia, whereas mark-up shocks appear to be significantly less persistent. The conditional variance decomposition shows that the total factor productivity is the main driver of output changes. It also accounts for a significant percentage of the inflation variability in the long run. Price mark-up shocks play a significant role in explaining price inflation and output - mainly in the short run.

Our analysis could be developed in several directions in future research. It would be interesting to concentrate on the estimation of fiscal multipliers before and after the crisis, also including some fiscal variables in our observable set to estimate fiscal rules and to compare their stabilizing properties to simple optimal rules. In a future study, more attention should be given to distinguishing revenue components due to automatic stabilization from others by a detailed analysis of various tax rules. 


\section{Appendix A - The IGEM model}

\subsection{Households}

Households consume the final non-tradable goods supplied by perfectly competitive firms, supply labor and rent out capital to firms. A continuum of households is distributed over a segment of mass one; a proportion $s_{N}$ is Non-Ricardian $(N)$, the other groups of households is Ricardian $(R)$. The representative Ricardian and Non-Ricardian household preferences depend on consumption $\left(C^{i}\right)$ and labor supplied $\left(L_{j}^{i}\right)$, which can be of four kinds: atypical $(A)$, low- $(L)$, high-skilled $(H)$, self-employed work $(S)$, i.e. $i \in\{N, R\}$ and $j \in \ell:=\{A, L, H, S\}$. In particular, the following specification is assumed:

$$
E_{0} \sum_{t=0}^{\infty} \beta^{t}\left[\log \left(C_{t}^{i}-h_{i} \bar{C}_{t-1}^{i}\right)+\sum_{j \in \ell} \frac{\omega_{j}}{1-v_{j}} s_{j}^{i}\left(1-L_{j, t}^{i}\right)^{1-v_{j}}\right], \quad i \in\{R, N\}
$$

where $E_{0}$ is the expectations operator conditional on information available at time 0 , and $\beta \in(0,1)$ represents the subjective discount factor; $h, \omega, v$ are commonly used preference parameters. Preferences display external habit formation in consumption and $h \in[0,1)$ is the habit coefficient $\left(\bar{C}_{t-1}\right.$ the lagged aggregate consumption, taken as given by each household).

The terms $s_{j}^{i}$ denote the share of households' members able to work in the $j$ activity $\left(\sum_{j \in \ell} s_{j}^{i}=1\right)$. The shares of workers present in the labor market by their type are then $s_{i}=s_{i}^{N} s_{N}+s_{i}^{R}\left(1-s_{N}\right)$ for $i \in \ell{ }^{13}$

The household's flow real budget constraint is:

$$
\begin{aligned}
& \frac{\left(1+\tau_{t}^{C}\right) P_{C, t}}{P_{t}} C_{t}^{i}+\phi^{i} \frac{P I_{t}^{R}+F I_{t}^{R}}{P_{t}}=\sum_{j \in \ell} s_{j}^{i} \frac{\left(1-\tau_{t}^{j}\right) W_{t}^{j}}{P_{t}} L_{j, t}^{i}+\operatorname{Tr}^{i}+ \\
&-T_{t}^{i}-\sum_{j \in \ell} s_{j}^{i} \frac{\Gamma_{j, t}^{W}}{P_{t}} Y_{t}+\phi^{R}\left[P R O_{t}^{R}+K S R_{t} \frac{P_{I, t}}{P_{t}} u_{t} K_{t}^{R}\right], \quad i \in\{R, N\}
\end{aligned}
$$

where $\phi^{i}$ is a dichotomous variable equal to 1 for Ricardians and zero, otherwise.

All kinds of households consume $\left(C_{t}^{i}\right)$, receive a nominal wages for each kind of labor input $j\left(L_{j, t} W_{j, t} / P_{t}\right)$, according to the share supplied, and transfers from

\footnotetext{
${ }^{13}$ Ricardians can be hired as atypical and low-skilled workers, while Non-Ricardians can be hired as atypical and low-skilled workers; thus, $s_{S}^{N}=s_{H}^{N}=s_{A}^{R}=0$. It follows that $s_{A}=s_{S}^{N} s_{N}$, $s_{L}=s_{L}^{N} s_{N}+s_{L}^{R}\left(1-s_{N}\right), s_{H}=s_{H}^{R}\left(1-s_{N}\right), s_{S}=s_{S}^{R}\left(1-s_{N}\right)$.
} 
the government $\left(T r^{i}\right)$; they pay lump-sum taxes $\left(T^{i}\right)$, consumption taxes (at a rate $\tau_{t}^{C}$ ), and wage income taxes and contributions to social security (at rates $\tau_{t}^{j}$ ). Households also face quadratic adjustment $\operatorname{costs}\left(\Gamma_{j, t}^{W}\right)^{14}$ for indexed nominal wage, later defined in details.

The dichotomous variable $\phi^{i}$ rules out from the constraint of Non-Ricardian households the decisions regarding physical and financial investments $\left(P I^{R}\right.$ and $\left.F I^{R}\right)$ and their revenues, i.e. dividends $\left(P R O^{R}\right)$, from the intermediate goods firms, and (per unit) capital service net return $\left(K S R_{t}\right)$. Ricardian households are in fact assumed to own three assets: government bonds, $B^{R}$, paying a gross nominal interest rate equal to $R$, foreign financial assets, $B_{F}^{R}$, paying a gross rate equal to $R^{*}$ adjusted for a risk premium $\rho^{F}$ (increasing in the aggregate level of foreign debt), and physical capital $K^{R}$.

Financial and physical investments are defined as $F I_{t}^{R}=B_{t}^{R}-R_{t-1} B_{t-1}^{R}+$ $S_{t}\left[B_{F, t}^{R}-\left(R_{t-1}^{*}+\rho_{t-1}^{F}\right) B_{F, t-1}^{R}\right]$ and $P I_{t}^{R}=P_{I, t}\left[I_{t}^{R}+\left(\Gamma_{t}^{I}+\Gamma_{t}^{u}\right) K_{t}^{R}\right]$, where $S_{t}$ is the nominal exchange rate defined as units of domestic currency per unit of foreign currency; $P_{I}$ the price of a unit of the investment good $\left(I_{t}^{R}\right) ; \Gamma^{I}$ and $\Gamma^{u}$ are investment and capital utilization convex adjustment costs (defined below).

Physical capital accumulates according to:

$$
K_{t+1}^{R}=\left(1-\delta_{K}\right) K_{t}^{R}+I_{t}^{R}
$$

where $\delta_{K}$ denotes the depreciation rate of physical capital. Investment decisions are subject to a convex adjustment cost of $\Gamma_{t}^{I} K_{t}^{R}$ units of the final good (with $\Gamma_{t}^{I}=\frac{1}{2} \gamma_{I} \mu_{t}^{I}\left(\frac{I_{t}^{R}}{K_{t}^{R}}-\delta_{K}\right)^{2}$ and $\left.\gamma_{I}>0\right)$. Owners of physical capital are also assumed to control the rate of utilization at which this factor is utilized, $u_{t}$. Using the stock of capital at a rate $u_{t}$ entails a cost in terms of the final good equal to $\Gamma_{t}^{u} K_{t}^{R}$ (with $\left.\Gamma_{t}^{u}=\gamma_{u_{1}}\left(u_{t}-1\right)+\frac{1}{2} \gamma_{u_{2}}\left(u_{t}-1\right)^{2}, \gamma_{u_{1}}, \gamma_{u_{2}}>0\right)$. Ricardians earn a capital service net return $K S R_{t}=\left(1-\tau_{t}^{K}\right) r_{t}^{K}+\tau_{t}^{K} \delta_{K}$, where $\tau^{K}$ are capital income taxes.

By maximizing (8) subject to the flow real budget constraint, we obtain consumption for both kinds of households. Moreover, considering the additional constraint (9), we also find the Ricardian demands for assets. Regarding labor supply, we must distinguish the different labor input types since labor markets feature different institutional details.

Specifically, self-employed workers, skilled and unskilled employees operate in

\footnotetext{
${ }^{14}$ Atypical workers do not face adjustment cost as they are assumed to be price takers.
} 
a monopoly competitive market. Thus, here representative professional orders or trade unions set the nominal wages, subject to quadratic wage adjustment costs. Specifically, in each of the three segments of the non-competitive labor market $i \in\left\{L_{L}, L_{H}, N_{S}\right\}$ operate a continuum of symmetric price makers; the elasticities of substitution between labor inputs $\left(\sigma_{i}>0\right)$ determine wage setters' market powers. In market $i$, the wage setter $j$ sets $W_{t}^{i}(j)$ to maximize households' expected utility (8), given the demand for its differentiated labor services (determined by $\sigma_{i}$ ) and subject to a convex adjustment costs function: $\Gamma_{i, t}^{W}=\frac{\gamma_{i}^{W}}{2}\left(\frac{W_{t}^{i}(j) / W_{t-1}^{i}(j)}{\Pi_{t-1}^{\kappa} \bar{\Pi}^{1-\kappa} W}-1\right)^{2} Y_{t}$ for $i \in \ell$, where $\gamma_{i}^{W}>0$ and $\Pi_{t-1}^{\kappa_{W}} \bar{\Pi}^{1-\kappa_{W}}$ is a geometric average of past gross $\left(\Pi_{t-1}^{W}\right)$ and long-run inflation $\left(\bar{\Pi}^{W}\right)$, where the weight of past inflation is determined by the indexation parameter $\kappa_{W} \in[0,1]$.

As the atypical sector is a competitive market, workers are price takers (there is no union coverage and non-wage adjustment cost, i.e. $\gamma_{A}^{W}=0$ ). The labor supply equation is then simply obtained by solving the optimization problem of the typical Non-Ricardian household (equating the real wage, $W_{t}^{A} / P_{t}$, to the marginal rate of substitution between leisure and consumption). Remember that, by assumption, only Non-Ricardian households supply labor services.

\subsection{Firms}

On the supply side, the economy presents four sectors: i) tradable intermediate good sector; ii) export sector; iii) import sector; iv) final good sector.

In the tradable sector, a continuum of monopolistically competitive firms indexed by $j \in[0,1]$ produces single tradable differentiated intermediate goods by using labor and physical capital as factor inputs. The typical firm $j$ uses labor inputs and capital to produce intermediate goods $Y_{t}(j)$ according to the following technology:

$$
Y_{t}(j)=A_{t}\left[N_{t}^{H L}(j)^{\alpha_{L}} N_{t}^{S A}(j)^{\alpha_{N}}\left(u_{t} K_{t}(j)\right)^{1-\alpha_{L}-\alpha_{N}}\right]^{1-\alpha_{G}}\left(G_{t}^{K}\right)^{\alpha_{G}}
$$

where $A_{t}$ denotes the total factor productivity, $N_{t}^{H L}$ and $N_{t}^{S A}$ denote CES aggregates of labor inputs hired; other symbols are strictly positive production parameters (with $\alpha_{G}<1, \alpha_{L}+\alpha_{N}<1$ ). $N_{t}^{H L}$ represents a combination of skilled and unskilled labor inputs hired in less competitive markets, while $N_{t}^{S A}$ includes labor inputs hired in the form of more flexible labor patterns. $G_{t}^{K}$ is the stock of govern- 
ment capital whose level depends on the public infrastructure investment decisions $I_{t}^{G}$ and evolves as $G_{t}^{K}=\left(1-\delta_{G}\right) G_{t-1}^{K}+I_{t}^{G}$. The labor aggregates are defined as: $N_{t}^{H L}=\left[\sum_{i \in\{H, L\}} e_{i} N_{i, t}^{\frac{\sigma_{H L}-1}{\sigma_{H L}}}\right]^{\frac{\sigma_{H L}}{\sigma_{H L}-1}}$ and $N_{t}^{S A}=\left[\sum_{i \in\{S, A\}} e_{i} N_{i, t}^{\frac{\sigma_{S A}-1}{\sigma_{S A}}}\right]^{\frac{\sigma_{S A}}{\sigma_{S A}-1}} \cdot{ }^{15} \mathrm{La}-$ bor inputs $N_{L, t}, N_{H, t}, N_{S, t}$, are, in turn, CES bundles of differentiated labor inputs with elasticity of substitution equal to $\sigma_{L}, \sigma_{H}$ and $\sigma_{S}$, respectively.

Given the production function, the objective of each firm $j$ is to maximize the sum of expected discounted real profits by setting the optimal price $P_{t}(j)$ and making choices about labor inputs and physical capital, given the available technology (10), the standard demand schedule for variety $j, Y_{t}(j)=\left(P_{t}(j) / P_{t}\right)^{-\theta_{Y}} Y_{t}$, quadratic adjustment costs on price setting and on labor inputs changes. Quadratic adjustment costs on price setting are $\Gamma_{t}^{P}=\frac{\gamma_{P}}{2}\left(\frac{P_{t}(j) / P_{t-1}(j)}{\Pi_{t-1}^{\kappa_{P}} \bar{\Pi}^{1-\kappa_{P}}}-1\right)^{2} Y_{t}$, with $\gamma_{P}>0$ and $\kappa_{P} \in[0,1]$ denoting weight of past inflation in the indexation. Quadratic adjustment costs on the four labor inputs changes are: ${ }^{16} \Gamma_{i}^{L}=\frac{\gamma_{i}^{L}}{2}\left(\frac{N_{i, t}(j)}{N_{i, t-1}(j)}-1\right)^{2} Y_{t}$ for $i \in \ell$, where $\gamma_{i}^{W}>0$. Firms are also assumed to pay social contributions at rates $\tau_{f}^{H}, \tau_{f}^{L}, \tau_{f}^{A}$ and $\tau_{f}^{S}$, respectively for skilled and unskilled employees, atypical workers and self-employed workers, and may receive incentives in the form of subsidies for hiring workers (with the exception of self-employed) at the differentiated rates $s u b^{H}, s u b^{L}$, and $s u b^{A}$.

In the export sector, a continuum of monopolistically-competitive-exporting firms transforms domestic intermediate goods into exportable goods using a linear technology. Exporters set the price for their product at a markup over their marginal cost. The price set by the exporter in foreign currency for the good $j, P_{X, t}(j)$, maximizes the expected discounted value of future profits, taking as given the exchange rate $S_{t}$ and the world demand for good $j$, i.e., $E X P_{t}(j)=$ $\left(P_{X, t}(j) / P_{X, t}\right)^{-\theta_{E X P}} E X P_{t}$, where $\theta_{E X P}>1$ is the elasticity of substitution between tradable goods, $E X P_{t}$ denotes the total demand of exportations, and $P_{X, t}=$ $\left[\int_{0}^{1} P_{X, t}(j)^{1-\theta_{E X P}} d j\right]^{\frac{1}{1-\theta_{E X P}}}$ is the export price index. Exporting firms are subject to adjustment costs: $\Gamma_{t}^{P_{X}}=\frac{\gamma_{E X P}}{2}\left[\frac{P_{X, t}(j) / P_{X, t-1}(j)}{\Pi_{t-1}^{* \kappa} E X \bar{\Pi}^{* 1-\kappa} E X P}-1\right]^{2} E X P_{t}$, which are measured by $\gamma_{E X P}>0 ; \Pi_{t-1}^{* \kappa_{E X P}} \bar{\Pi}^{* 1-\kappa_{E X P}}$ is a geometric average of past (gross) and

\footnotetext{
${ }^{15}$ We have dropped index $j$ to save on notation. Note that coefficients $\left(e_{i}\right)$ can be disentangled to capture different effects of shock in the production functions. See Annicchiarico et al. (2013a).

${ }^{16}$ It is assumed that $0<\gamma_{N_{A}}<\gamma_{N_{S}}<\gamma_{L_{H}}=\gamma_{L_{L}}$ in order to capture the higher costs associated with changes in the labor inputs related to workers with stable contracts.
} 
long-run inflation prevailing in the foreign market (the weight of past inflation is determined by the indexation parameter $\left.\kappa_{E X P} \in[0,1]\right)$.

Similarly, in the competitive import sector, a continuum of monopolisticallycompetitive-importing firms transforms foreign intermediate goods into importable goods using a linear technology. Importers set prices in local currency as a markup over the import price of intermediate goods produced abroad and facing a demand $I M P_{t}(j)=\left(P_{M, t}(j) / P_{t}^{M}\right)^{-\theta_{I M P}} I M P_{t}$ where $\theta_{I M P}>1$ is the elasticity of substitution between imported goods, $I M P_{t}$ denotes the total demand of imported goods, $P_{M, t}(j)$ is the price of the imported good expressed in domestic currency and $P_{M, t}$ is the ideal import price index, given by $P_{M, t}=\left[\int_{0}^{1} P_{M, t}(j)^{1-\theta_{I M P}} d j\right]^{\frac{1}{1-\theta_{I M P}}}$. The quadratic cost function to adjusting prices is $\Gamma_{t}^{P_{M}}=\frac{\gamma_{I M P}}{2}\left[\frac{P_{M, t}(j) / P_{M, t-1}(j)}{\Pi_{t-1}^{\kappa} I M P \bar{\Pi}^{1-\kappa_{I M P}}}-1\right]^{2} I M P_{t}$, where $\gamma_{I M P}>0$ and $\kappa_{I M P} \in[0,1]$.

The final non-tradable good is competitive. The representative firm produces the final good $E_{t}$ (which can be used for private and public consumption and for private and public investment) by combining a bundle of domestically produced intermediate goods $Y_{H, t}$ with a bundle of imported intermediate goods $I M P_{t}$ according to a CES technology:

$$
Y_{C, t}=\left[\left(1-\alpha_{I M P}\right)^{\frac{1}{\sigma_{I M P}}} Y_{H, t}^{\frac{\sigma_{I M P}-1}{\sigma_{I M P}}}+\alpha_{I M P} \frac{1}{\sigma_{I M P}} I M P_{t}^{\frac{\sigma_{I M P}-1}{\sigma_{I M P}}}\right]^{\frac{\sigma_{I M P}}{\sigma_{I M P}-1}}
$$

where $\sigma_{I M P}$ is the elasticity of substitution between domestically produced goods and internationally produced goods, $\alpha_{I M P}$ represents the share of foreign intermediate goods used in the production of the final goods and $Y_{H, t}=\left[\int_{0}^{1} Y_{H, t}(j)^{\frac{\theta_{Y}-1}{\theta_{Y}}} d j\right]^{\frac{\theta_{Y}}{\theta_{Y}-1}}$, $I M P_{t}=\left[\int_{0}^{1} I M P_{t}(j)^{\frac{\theta_{I M P}-1}{\theta_{I M P}}} d j\right]^{\frac{\theta_{I M P}}{\theta_{I M P}-1}}$, where $\theta_{Y}, \theta_{I M P}>1$ denote the elasticities of substitution between the differentiated intermediate goods produced at home and abroad. Perfect competition and free entry imply zero profit, $P_{t}=$ $\left[\int_{0}^{1} P_{t}(j)^{1-\theta_{Y}} d j\right]^{\frac{1}{1-\theta_{Y}}}$ (which defines the economy aggregate price index), and $P_{M, t}=$ $\left[\int_{0}^{1} P_{M, t}(j)^{1-\theta_{I M P}} d j\right]^{\frac{1}{1-\theta_{I M P}}}$. 


\subsection{Closing the model}

The model is closed considering public and foreign sectors and market-clearing conditions. With regard to the public sector and foreign sector, the government issues nominal debt in the form of interest-bearing bonds. Public consumption and investment, interest payments on outstanding public debt, transfers to households, and subsidies to firms are financed by taxes on capital, labor and consumption, and/or by issuance of new bonds. To ensure that the fiscal budget constraint is respected, it is assumed that the tax authority adopts a tax rule that responds to public debt variations. The external monetary authority (ECB) controls the nominal interest rate, which responds to some extent to domestic conditions. The development of the net foreign asset position depends on the current account surplus, and therefore on the decisions of firms, households and government. The transmission mechanism from internal to external variables is further complicated by the assumption that the domestic exporting and importing firms have some market power in the prices they set, so that the net external position depends on conditions in both financial and goods markets.

The public sector is characterized by two equations defining the public deficit dynamics and the tax rule. Specifically, the government purchases final goods for consumption $C_{t}^{G}$ and investment $I_{t}^{G}$, makes transfers to households $T r_{t}$, gives subsidies to intermediate goods producers $S U B_{t}$, receives lump-sum taxes $T_{t}$ and tax payments on labor income, consumption and capital $T_{t}^{L}, T_{t}^{C}, T_{t}^{K}$, and issues nominal bonds $B_{t}$ (in real terms $B_{t}^{r}$ ). The real deficit $\left(D_{t}\right)$ dynamics is then given by:

$$
D_{t}=\left(R_{t-1}-1\right) \frac{B_{t-1}^{r}}{\Pi_{t}}+\frac{P_{C, t}}{P_{t}} G_{t}+\frac{P_{I G, t}}{P_{t}} I_{t}^{G}+T r_{t}-T_{t}-\sum_{\Lambda_{t} \in \Lambda} \Lambda_{t}+S U B_{t},
$$

where $\Lambda_{t} \in\left\{T_{t}^{L}, T_{t}^{C}, T_{t}^{K}\right\}$ are determined by the given tax rates on labor, consumption and capital. The tax dynamics are described by a fiscal rule, which captures the tax response to the public finance indicators (debt and deficit) and the stance of stabilization policies. Formally, the fiscal rule in deviations from the steady state is:

$$
\tilde{T}_{t}=T_{B} \frac{\tilde{B}_{t-1}^{r}}{\Pi_{t}}+T_{D} \tilde{D}_{t}+T_{Y} \tilde{Y}_{t}
$$

where $T_{B}, T_{D}, T_{Y}$ are policy parameters. 
The monetary authority adopts a Taylor-type interest rate rule, which is specified as follows:

$$
\frac{R_{t}}{\bar{R}}=\left(\frac{R_{t-1}}{\bar{R}}\right)^{\iota_{r}}\left[\left(\frac{\Pi_{t}}{\bar{\Pi}}\right)^{\iota_{\pi}}\left(\frac{Y_{t}}{\bar{Y}}\right)^{\iota_{y}}\left(\frac{S_{t}}{\bar{S}}\right)^{\iota_{s}}\right]^{1-\iota_{r}} e^{u_{t}^{R}}
$$

where $\bar{R}$ is the equilibrium nominal interest rate, $\bar{\Pi}$ is the monetary authority inflation target, $\bar{S}$ is the long-run (steady state) exchange rate, $\bar{Y}$ is the steady state output, and $\iota_{R}, \iota_{\Pi}, \iota_{Y}, \iota_{S}$ are policy parameters.

The economy's net foreign asset position denominated in domestic currency evolves as:

$$
S_{t} B_{F, t}=\left(R_{t-1}^{*}+\rho_{t-1}^{F}\right) S_{t} B_{F, t-1}+S_{t} P_{X, t} E X P_{t}-P_{M, t} I M P_{t}
$$

where the risk premium $\rho_{t}^{F}$ is assumed to be increasing in the aggregate level of foreign debt. The following functional form for the risk premium is used: $\rho_{t}^{F}=$ $-\varphi^{F}\left(e^{B_{t}^{r, F}-\bar{B}^{r, F}}-1\right)$, where $\varphi^{F}$ is a positive parameter, $B_{t}^{r, F}=S_{t} B_{F, t} / P_{t}$ and $\bar{B}^{r, F}$ is the steady state level of net foreign assets in real terms (see Schmitt-Grohé and Uribe, 2003). Clearly, in the steady-state $\rho_{t}^{F}=0$.

Since only Ricardian households hold financial assets, accumulate physical capital and own domestic firms, equilibrium satisfied in aggregate: $\left(1-s_{N}\right) B_{t}^{R}=B_{t}$, $\left(1-s_{N}\right) B_{F, t}^{R}=B_{F, t},\left(1-s_{N}\right) I_{t}^{R}=I_{t},\left(1-s_{N}\right) K_{t}^{R}=K_{t},\left(1-s_{N}\right) P R O_{t}^{R}=P R O_{t}$ while aggregate consumption is $C_{t}=\left(1-s_{N}\right) C_{t}^{R}+s_{N} C_{t}^{N}$.

Equilibrium in the labor markets requires that the quantity of each category of labor employed in the intermediate good sector must be equal to supply. Labor market clearing conditions are then $N_{i, t}=\left(1-s_{N}\right) L_{i, t}^{R}+s_{N} L_{i, t}^{N}$ for $i \in \ell$. Since the final good can be used for private and public consumption and for private and public investment, we have $P_{C, t}=P_{I, t}=\left[\left(1-\alpha_{I M P}\right) P_{t}^{1-\sigma_{I M P}}+\alpha_{I M P} P_{M, t}^{1-\sigma_{I M P}}\right]^{\frac{1}{1-\sigma_{I M P}}}$, and $P_{M, t} I M P_{t}+P_{t} Y_{H, t}=P_{C, t}\left(C_{t}+C_{t}^{G}+I_{t}+I_{t}^{G}\right)$. Market clearing in the intermediate goods market requires $Y_{t}=Y_{H, t}+S_{t} \frac{P_{X, t}}{P_{t}} E X P_{t}$.

The resource constraint of the economy immediately follows:

$$
Y_{t}=\frac{P_{t}^{C}\left(C_{t}+C_{t}^{G}+I_{t}+I_{t}^{G}\right)}{P_{t}}+\frac{S_{t} P_{X, t} E X P_{t}-P_{M, t} I M P_{t}}{P_{t}}+\Gamma_{t}
$$

where $\Gamma_{t}$ is the sum of all the $\Gamma$-adjustment costs. 


\section{Appendix B - Estimated model}

This appendix reports the equations of the stochastic estimated version of IGEM.

Consumption of the Ricardian Households:

$$
\frac{P_{t}}{P_{C, t}} \frac{1}{\left(1+\tau_{t}^{C}\right)\left(C_{t}^{R}-h_{R} C_{t-1}^{R}\right)}=\beta E_{t} \frac{P_{t+1}}{P_{C, t+1}} \frac{1}{\left(1+\tau_{t+1}^{C}\right)\left(C_{t+1}^{R}-h_{R} C_{t}^{R}\right)} \frac{R_{t}}{\Pi_{t+1}} Z_{t}
$$

Lagrangian Multiplier of the Ricardian and Non-Ricardian Households:

$$
\lambda_{t}^{i}=\frac{P_{t}}{P_{C, t}} \frac{Z_{t}}{\left(1+\tau_{t}^{C}\right)\left(C_{t}^{i}-h_{i} C_{t-1}^{i}\right)}, \quad i \in\{R, N\}
$$

Consumption of the Non-Ricardian Households:

$$
\begin{aligned}
C_{t}^{N}= & \frac{P_{t}}{\left(1+\tau_{t}^{C}\right) P_{C, t}}\left[\frac{s_{A}\left(1-\tau_{t}^{A}\right) W R_{t}^{A} L_{A, t}}{s_{N}}+\right. \\
& \left.\frac{\lambda^{L} s_{L}}{s_{N}}\left(\left(1-\tau_{t}^{i}\right) W R_{t}^{i} L_{L, t}-\frac{\gamma_{L}^{W}\left(\Omega_{t}^{i}-1\right)^{2} Y_{t}}{2}\right)-T_{t}^{N}+\operatorname{Tr}_{t}^{N}\right]
\end{aligned}
$$

with $\Omega_{t}^{i}=\frac{\Pi_{t} W R_{t}^{i} / W R_{t-1}^{i}}{\Pi_{t-1}^{\kappa} W \bar{\Pi}^{1-\kappa} W}$ for $i \in\{S, H, L\}$.

Aggregate Consumption:

$$
C_{t}=s_{N} C_{t}^{N}+\left(1-s_{N}\right) C_{t}^{R}
$$

Wage Equation of Self-Employed Labor Workers:

$$
\begin{aligned}
\left(1-\tau_{t}^{S}\right) W R_{t}^{S}= & \frac{\omega_{S} \sigma_{S}\left(1-L_{S, t}\right)^{-v_{S}}}{\lambda_{t}^{R}\left(\sigma_{S}-1\right)}-\frac{\gamma_{S}^{W} \Omega_{t}^{S}\left(\Omega_{t}^{S}-1\right) Y_{t}}{\left(\sigma_{S}-1\right) L_{S, t}}+ \\
& +\beta \frac{\lambda_{t+1}^{R}}{\lambda_{t}^{R}} \frac{\gamma_{S}^{W} \Omega_{t+1}^{S}\left(\Omega_{t+1}^{S}-1\right) Y_{t+1}}{\left(\sigma_{S}-1\right) L_{S, t}}
\end{aligned}
$$

Wage Equation of Skilled Employees:

$$
\begin{aligned}
\left(1-\tau_{t}^{H}\right) W R_{t}^{H}= & \exp \left(\mu_{t}^{W_{H}}\right) \frac{\omega_{H} \sigma_{H}\left(1-L_{H, t}\right)^{-v_{H}}}{\lambda_{t}^{R}\left(\sigma_{H}-1\right)}-\frac{\gamma_{H}^{W} \Omega_{t}^{H}\left(\Omega_{t}^{H}-1\right) Y_{t}}{\left(\sigma_{H}-1\right) L_{H, t}}+ \\
& +\beta \frac{\lambda_{t+1}^{R}}{\lambda_{t}^{R}} \frac{\gamma_{H}^{W} \Omega_{t+1}^{H}\left(\Omega_{t+1}^{H}-1\right) Y_{t+1}}{\left(\sigma_{H}-1\right) L_{H, t}}+\mu_{t}^{W_{H}}
\end{aligned}
$$


Wage Equation of Unskilled Employees:

$$
\begin{aligned}
\left(1-\tau_{t}^{L}\right) W R_{t}^{L}= & \exp \left(\mu_{t}^{W_{L}}\right) \frac{\omega_{L} \sigma_{L}\left(1-L_{L, t}\right)^{-v_{L}}}{\Lambda_{t}\left(\sigma_{L}-1\right)}-\frac{\Lambda_{t} \gamma_{L}^{W} \Omega_{t}^{L}\left(\Omega_{t}^{L}-1\right) Y_{t}}{\left(\sigma_{L}-1\right) L_{L, t}}+ \\
& +\beta \frac{\Lambda_{t+1}}{\Lambda_{t}} \frac{\gamma_{L}^{W} \Omega_{t+1}^{L}\left(\Omega_{t+1}^{L}-1\right) Y_{t+1}}{\left(\sigma_{L}-1\right) L_{L, t}} \mu_{t}^{W_{L}}
\end{aligned}
$$

where $\Lambda_{t}=\left[\left(1-I^{N R} \lambda^{L}\right) \lambda_{t}^{R}+I^{N R} \lambda^{L} \lambda_{t}^{N}\right]$.

Supply of Atypical Labor Services:

$$
W R_{t}^{A}\left(1-\tau_{t}^{A}\right)=\frac{\omega_{A}\left(1-N_{A, t}\right)^{-v_{A}}}{\lambda_{t}^{N}}
$$

Demand of Skilled Labor as Employees:

$$
\begin{aligned}
W R_{t}^{H}\left(1-s u b_{t}^{H}+\tau_{f, t}^{H}\right)= & \alpha_{L}\left(1-\alpha_{G}\right) M C_{t} \frac{Y_{t}}{N_{t}^{H L}} e_{H}^{\frac{\sigma_{H L}-1}{\sigma_{H L}}}\left(\frac{N_{t}^{H L}}{N_{H, t}}\right)^{\frac{1}{\sigma_{H L}}}+ \\
& -\gamma_{H}^{L}\left(\frac{N_{H, t}}{N_{H, t-1}}-1\right) \frac{1}{N_{H, t-1}} Y_{t}+ \\
& +\beta \frac{\lambda_{t+1}^{R}}{\lambda_{t}^{R}} \gamma_{H}^{L}\left(\frac{N_{H, t+1}}{N_{H, t}}-1\right) \frac{N_{H, t+1}}{N_{H, t}^{2}} Y_{t+1}
\end{aligned}
$$

Demand of Unskilled Labor as Employees:

$$
\begin{aligned}
W R_{t}^{L}\left(1-s u b_{t}^{L}+\tau_{f, t}^{L}\right)= & \alpha_{L}\left(1-\alpha_{G}\right) M C_{t} \frac{Y_{t}}{N_{t}^{H L}} e_{L}^{\frac{\sigma_{H L}-1}{\sigma_{H L}}}\left(\frac{N_{t}^{H L}}{N_{L, t}}\right)^{\frac{1}{\sigma_{H L}}}+ \\
& -\gamma_{L}^{L}\left(\frac{N_{L, t}}{N_{L, t-1}}-1\right) \frac{Y_{t}}{N_{L, t-1}}+ \\
& +\beta \frac{\lambda_{t+1}^{R}}{\lambda_{T}^{R}} \gamma_{L}^{L}\left(\frac{N_{L, t+1}}{N_{L, t}}-1\right) Y_{t+1} \frac{N_{L, t+1}}{N_{L, t}^{2}}
\end{aligned}
$$

Demand of Self-Employed Labor:

$$
\begin{aligned}
& W R_{t}^{S}\left(1-s u b_{t}^{S}+\tau_{f, t}^{S}\right)=\alpha_{N}\left(1-\alpha_{G}\right) M C_{t} \frac{Y_{t}}{N_{t}^{S A}} e_{S}^{\frac{\sigma_{N}-1}{\sigma_{N}}}\left(\frac{N_{t}^{S A}}{N_{S, t}}\right)^{\frac{1}{\sigma_{N}}}+ \\
& -\gamma_{S}^{L}\left(\frac{N_{S, t}}{N_{S, t-1}}-1\right) Y_{t} \frac{1}{N_{S, t-1}}+\beta \frac{\lambda_{t+1}^{R}}{\lambda_{T}^{R}} \gamma_{S}^{L}\left(\frac{N_{S, t+1}}{N_{S, t}}-1\right) Y_{t+1} \frac{N_{S, t+1}}{N_{S, t}^{2}}
\end{aligned}
$$


Demand of Atypical Labor:

$$
\begin{aligned}
W R_{t}^{A}\left(1+\tau_{f, t}^{A}\right)=\alpha_{N}(1 & \left.-\alpha_{G}\right) M C_{t} \frac{Y_{t}}{N_{t}^{S A}} e_{A}^{\frac{\sigma_{N}-1}{\sigma_{N}}}\left(\frac{N_{t}^{S A}}{N_{A, t}}\right)^{\frac{1}{\sigma_{N}}}+ \\
& -\gamma_{A}^{L}\left(\frac{N_{A, t}}{N_{A, t-1}}-1\right) Y_{t} \frac{1}{N_{A, t-1}}+ \\
& +\beta \frac{\lambda_{t+1}^{R} \gamma_{A}^{L}\left(\frac{N_{A, t+1}}{N_{T}^{R}}-1\right) Y_{t+1} \frac{N_{A, t+1}}{N_{A, t}^{2}}}{}
\end{aligned}
$$

Equilibrium in the Labor Market:

$$
N_{i, t}=\left(1-s_{N}\right) L_{i, t}^{R}+s_{N} L_{i, t}^{N} \quad \text { for } i \in \ell
$$

Production Function of the Intermediate-Goods Producers:

$$
Y_{t}=A_{t}\left[\left(e^{\mu_{t}^{L}} N_{t}^{H L}\right)^{\alpha_{L}}\left(e^{\mu_{t}^{L}} N_{t}^{S A}\right)^{\alpha_{N}}\left(u_{t} K_{t}\right)^{1-\alpha_{L}-\alpha_{N}}\right]^{1-\alpha_{G}}\left(G_{t}^{K}\right)^{\alpha_{G}}
$$

Employees Labor CES Aggregate:

$$
N_{t}^{H L}=\left[\sum_{i \in\{H, L\}} e_{i} N_{i, t}^{\frac{\sigma_{H L}-1}{\sigma_{H L}}}\right]^{\frac{\sigma_{H L}}{\sigma_{H L}-1}}
$$

Self-Employed and Atypical Labor CES Aggregate:

$$
N_{t}^{S A}=\left[\sum_{i \in\{S, A\}} e_{i} N_{i, t}^{\frac{\sigma_{S A}-1}{\sigma_{S A}}}\right]^{\frac{\sigma_{S A}}{\sigma_{S A}-1}}
$$

Physical Capital Accumulation Equation:

$$
K_{t+1}=\left(1-\delta_{K}\right) K_{t}+I_{t}
$$

Investment Equation

$$
q_{t}-1=\gamma_{I} \mu_{t}^{I}\left(\frac{I_{t}}{K_{t}}-\delta_{K}\right)-t c r_{t}^{K}
$$


Tobin's Q:

$$
q_{t}=\beta E_{t} \frac{\lambda_{t+1}^{R}}{\lambda_{t}^{R} \Pi_{t+1}}\left[K S R_{t+1} u_{t}+\left(1-\delta_{K}\right) q_{t+1}-\sum_{i \in\{I, u\}} \Gamma_{t}^{i}+\frac{I_{t+1}}{1-s_{N}} \frac{\partial \Gamma_{t}^{I}}{\partial I_{t+1}^{R}}\right] \text { prem }_{t}
$$

Demand of Capital:

$$
r_{t}^{k}=\frac{P_{t}}{P_{t}^{I}} \frac{\left(1-\alpha_{G}\right)\left(1-\alpha_{L}-\alpha_{N}\right) M C_{t} Y_{t}}{u_{t} K_{t}}
$$

Capital Utilization:

$$
u_{t}^{K}=1-\frac{\gamma_{u_{1}}-\left(1-\tau_{t}^{K}\right) r_{t}^{K}-\tau_{t}^{K} \delta_{K}}{\gamma_{u_{2}}}
$$

Real Profits of Intermediate Goods Producers:

$$
P R O_{t}=Y_{t}-\sum_{j \in \ell}\left(1-s u b_{t}^{i}+\tau_{f, t}^{i}\right) W R_{t}^{i} N_{t}^{i}-\frac{P_{t}^{I}}{P_{t}} r_{t}^{K} u_{t}^{K} K_{t}-\Gamma_{t}^{P}-\sum_{j \in \ell} \Gamma_{i}^{L}
$$

Inflation Equation:

$$
1-\gamma_{p}\left(\frac{\Pi_{t}}{\psi_{t}^{P}}-1\right) \frac{\Pi_{t}}{\psi_{t}^{P}}+\beta \gamma_{p} E_{t} \frac{\lambda_{t+1}^{R}}{\lambda_{t}^{R}}\left(\frac{\Pi_{t+1}}{\psi_{t+1}^{P}}-1\right) \frac{\Pi_{t+1}}{\psi_{t+1}^{P}} \frac{Y_{t+1}}{Y_{t}}=\theta_{Y}\left(1-e^{\mu_{t}} M C_{t}\right)
$$

Accumulation of Public Capital:

$$
G_{t+1}^{K}=I_{t}^{G}+\left(1-\delta_{K G}\right) G_{t}^{K}
$$

Public Debt Dynamics:

$$
B R_{t}=\frac{B R_{t-1}}{\Pi_{t}}+D R_{t}
$$

Transfers:

$$
\operatorname{Tr}_{t}=s_{N^{T R}} \operatorname{Tr}_{t}^{N}+\left(1-s_{N^{T R}}\right) \operatorname{Tr}_{t}^{R}
$$

Labor Taxes and Social Contributions:

$$
L T A X_{t}=\sum_{j \in \ell} s_{j} L_{j, t} W R_{t}^{j}\left(\tau_{t}^{j}+\tau_{f, t}^{j}\right)
$$


Consumption Taxes:

$$
T V A T_{t}=\tau_{t}^{C} \frac{P_{C, t}}{P_{t}} C_{t}
$$

Capital Taxes Net of Tax Credit:

$$
K T A X_{t}=\frac{P_{t}^{I}\left(\tau_{t}^{K}\left(r_{t}^{K}-\delta^{K}\right) u_{t}^{K} K_{t}-t c r_{t}^{K} I_{t}\right)}{P_{t}}
$$

Fiscal Rule:

$$
P_{t} T_{t}=P_{t} \bar{T}+T_{B} B_{t-1}+T_{D} D_{t}+T_{Y} P_{t}\left(Y_{t}-Y_{t-1}\right)
$$

Lump-Sum Taxes Levied on Ricardian Households:

$$
T_{t}^{R}=\left(1-s_{T A X}^{N}\right) T_{t}
$$

Tax Profit:

$$
P R O T A X_{t}=\tau_{t}^{P R O} P R O X_{t}
$$

Government Deficit:

$$
D_{t}=\left(R_{t-1}-1\right) \frac{B_{t-1}^{r}}{\Pi_{t}}+\frac{P_{C, t}}{P_{t}} G_{t}+\frac{P_{I G, t}}{P_{t}} I_{t}^{G}+T r_{t}-T_{t}-\sum_{\Lambda_{t} \in \Lambda} \Lambda_{t}+S U B_{t},
$$

Resource Constraint of the Economy:

$$
Y_{t}=\frac{P_{t}^{C}\left(C_{t}+C_{t}^{G}+I_{t}+I_{t}^{G}\right)}{P_{t}}+\frac{S_{t} P_{X, t} E X P_{t}-P_{M, t} I M P_{t}}{P_{t}}+\Gamma_{t}
$$

Interest Rate Rule:

$$
\frac{R_{t}}{\bar{R}}=\left(\frac{R_{t-1}}{\bar{R}}\right)^{\iota_{r}}\left[\left(\frac{\Pi_{t}}{\bar{\Pi}}\right)^{\iota_{\pi}}\left(\frac{Y_{t}}{\bar{Y}}\right)^{\iota_{y}}\left(\frac{S_{t}}{\bar{S}}\right)^{\iota_{s}}\right]^{1-\iota_{r}} e^{u_{t}^{R}}
$$

Imports Demand:

$$
I M P_{t}=\alpha_{I M P}\left(\frac{P_{M, t}}{P_{C, t}}\right)^{-\sigma_{I M P}}\left(C_{t}+I_{t}+G_{t}+I_{t}^{G}\right)
$$

Exports Demand:

$$
E X P_{t}=\alpha_{E X P}\left(\frac{P_{X, t}}{P_{C, t}^{*}}\right)^{-\sigma_{E X P}} W D_{t}
$$


Import Price Inflation:

$$
\begin{aligned}
& \frac{\left(1-\theta_{I M P}\right) P_{M, t}+\theta_{I M P} S_{t} P_{t}^{*}}{P_{t}} I M P_{t}-\left(\frac{\Pi_{t}^{I M P}}{\psi_{t}^{I M P}}-1\right) \frac{\gamma_{I M P} I M P_{t} \Pi_{t}^{I M P}}{\psi_{t}^{I M P}}+ \\
& +\beta E_{t} \frac{\lambda_{t+1}^{R}}{\lambda_{t}^{R}}\left(\frac{\Pi_{t+1}^{I M P}}{\psi_{t+1}^{I M P}}-1\right) \frac{\gamma_{I M P} I M P_{t+1} \Pi_{t+1}^{I M P}}{\psi_{t+1}^{I M P}}=0
\end{aligned}
$$

Export Price Inflation:

$$
\begin{aligned}
& \frac{\theta_{E X P} P_{t}+\left(1-\theta_{E X P}\right) S_{t} P_{X, t}}{P_{t}} \\
& E X P_{t}-\left(\frac{\Pi_{t}^{E X P}}{\psi_{t}^{E X P}}-1\right) \frac{\gamma_{E X P} E X P_{t} \Pi_{t}^{E X P}}{\psi_{t}^{E X P}}+ \\
& +\beta E_{t} \frac{\lambda_{t+1}^{R}}{\lambda_{t}^{R}}\left(\frac{\Pi_{t+1}^{E X P}}{\psi_{t+1}^{E X P}}-1\right) \frac{\gamma_{E X P} E X P_{t+1} \Pi_{t+1}^{E X P}}{\psi_{t+1}^{E X P}}=0
\end{aligned}
$$

Domestic Consumption Price Index:

$$
P_{C, t} \equiv\left[\left(1-\alpha_{I M P}\right) P_{t}^{1-\sigma_{I M P}}+\alpha_{I M P} P_{M, t}^{1-\sigma_{I M P}}\right]^{\frac{1}{1-\sigma_{I M P}}}
$$

Euler Equation Related to Foreign Assets:

$$
S_{t} \lambda_{t}^{R}=\beta E_{t} \lambda_{t+1}^{R} \frac{R_{t}^{*}+\rho_{t}^{F}}{\Pi_{t+1}} S_{t+1}
$$

Foreign Assets Net Position in Real Terms:

$$
B R_{t}^{r, F}=\frac{R_{t-1}^{*}+\rho_{t-1}^{F}}{\Pi_{t}} \frac{S_{t}}{S_{t-1}} B R_{t-1}^{r, F}+\frac{S_{t} P_{X, t}}{P_{t}} E X P_{t}-\frac{P_{M, t}}{P_{t}} I M P_{t}
$$

Risk Premium:

$$
\rho_{t}^{F}=-\varphi^{F}\left(e^{B_{t}^{r, F}-B^{r, F}}-1\right)
$$

Market Clearing Condition:

$$
Y_{t}=X_{t}
$$

Investment Goods Price Level:

$$
P_{I, t}=P_{C, t}
$$

Import Price Indexation:

$$
\psi_{t}^{I M P}=\left(\Pi_{t-1}^{I M P}\right)^{K_{I M P}}\left(\Pi^{*}\right)^{1-K_{I M P}}
$$


Imported Good Price Level:

$$
P_{M, t}=\Pi_{t}^{I M P} P_{M, t-1}
$$

Domestic Final Good Inflation:

$$
\Pi_{t}=P_{t} / P_{t-1}
$$

Export Price Inflation:

$$
\Pi_{t}^{E X P}=P_{X, t} / P_{X, t-1}
$$

Price Indexation:

$$
\psi_{t}^{P}=\Pi_{t-1}^{\kappa_{P}} \bar{\Pi}^{1-\kappa_{P}}
$$

Export Price Indexation:

$$
\psi_{t}^{E X P}=\left(\Pi_{t-1}^{E X P}\right)^{\kappa_{E X P}} \bar{\Pi}^{1-\kappa_{E X P}}
$$

Wage Indexation:

$$
\psi_{t}^{W}=\Pi_{t-1}^{\kappa_{W}} \bar{\Pi}^{1-\kappa_{W}}
$$

Interest Rate Shock:

$$
u_{t}^{R}=\varepsilon_{t}^{R}
$$

Shock Public Expenditure:

$$
A R G_{t}=\rho_{G} A R G_{t-1}+\varepsilon_{t}^{G}
$$

TFP Shock:

$$
A R T F P_{t}=\rho_{T F P} A R T F P_{t-1}+\varepsilon_{t}^{T F P}
$$

Price Mark-up Shock:

$$
\mu_{t}=\rho_{\mu} \mu_{t-1}+\varepsilon_{t}^{\mu}
$$

Wage Mark-up Shock (High-Skilled):

$$
\mu_{t}^{W_{H}}=\rho_{\mu^{w}}^{H} \mu_{t-1}^{H_{L}}+\varepsilon_{t}^{w_{l h}}
$$


Wage Mark-up Shock (Unskilled):

$$
\mu_{t}^{W_{L}}=\rho_{\mu^{w}}^{L} \mu_{t-1}^{W_{L}}+\varepsilon_{t}^{w_{l l}}
$$

Preference Shock:

$$
Z_{t}=\rho_{Z} Z_{t-1}+\varepsilon_{t}^{Z}
$$

Investment Specific Shock:

$$
\mu_{t}^{I}=\rho_{L} \mu_{t-1}^{I}+\varepsilon_{t}^{I}
$$

Labor Intensity Shock:

$$
\mu_{t}^{L}=\rho_{L} \mu_{t-1}^{L}+\varepsilon_{t}^{L}
$$




\section{Appendix C - IGEM calibrations}

The model calibration follows Annicchiarico et al. (2013a) to whom we refer for more details.

The discount factor $\beta$ is equal to 0.99 , implying an annual real interest rate of $4 \%$. The rates of depreciation of private and public physical capital $\delta_{K}$ and $\delta_{G}$ are set to 0.025 implying a $10 \%$ annual depreciation rate of capital. The capital share in the intermediate goods production is equal to 0.3 , hence $1-\alpha_{L}-\alpha_{N}=0.3$. The labor shares are such that $\alpha_{L}=\alpha_{N}=0.35$. The CES parameters $\sigma_{L}$ and $\sigma_{N}$ are set at 1.4 according to Katz and Murphy (1992) estimates, as in QUEST III for Italy. As in the baseline IGEM, the contribution of public capital to production is neglected (i.e., $\alpha_{G}=0$ ).

The elasticities of substitution between domestic goods in the intermediate sector, $\theta_{Y}$, is set equal to 5 so to have a steady-state level of net markup equal to $25 \%$, which is consistent with the value set in the Italian version of QUEST III with $R \mathscr{E} D$ (see D'Auria et al., 2009). Since in IGEM tradable goods are produced in the intermediate sector, we also set the elasticities of substitution between imported and exported varieties, $\theta_{I M P}$ and $\theta_{E X P}$, at 5. The contribution of imported intermediate goods to the final good production, summarized by the parameter $\alpha_{I M P}$ is equal to 0.26 , while the elasticity of substitution between domestic and foreign intermediate varieties $\sigma_{I M P}$ is set at 1.1. Similarly, $\alpha_{E X P}=0.26$ and $\sigma_{I M P}=1.1$. The steady-state inflation is set equal to zero, $\Pi=1$. The same holds for foreign inflation.

Drawing on RCFL-ISTAT 2008 data set, labor categories are defined as follows. Employees are identified with those workers with a stable labor contract and eligible of labor protection, so belonging to the primary labor market. In the available data, this category amounts to $53 \%$ of the whole workforce, within this category the share of the employees with tertiary education corresponds to the skilled workers and accounts for $11 \%$ of the workers (i.e., $s_{H}=0.11$ ). The remaining share is identified with the unskilled employees (i.e., $s_{L}=0.42$ ). The share of self-employed workers older than 35 , is $21 \%$ and the model share $s_{S}$ is set accordingly. As a matter of fact, we exclude from this category of workers the young, since at early stages of their careers they tend to be precarious and face the same difficulties of the workers with atypical contracts. Hence, the last category of workers, labeled as "atypical", includes young self-employed, apprentices, temporary workers and other 
workers with atypical contracts characterized by weak security protection and low firing costs, so belonging to the secondary market. This residual fraction of workers amounts to $26 \%$ (i.e., $s_{A}=0.26$ ). The share of liquidity constrained households is $26 \%$.

According to the estimates based on EconLav microsimulation model, the Frisch elasticity of labor supply for the employees is 0.30 , while for the atypical component of the labor force the Frisch elasticity is equal to 0.35. For the self-employed workers we set the Frisch elasticity at 0.30 , since it is conjectured that the reactivity of their labor supply to changes in their remuneration is closer to that experienced by workers with stable contracts. In line with the literature, elasticities of substitution between different varieties of labor $\sigma_{L}, \sigma_{H}$, and $\sigma_{S}$ are all set at 2.65 (see Forni et al., 2010), reflecting the limited competition protecting the insiders. Habit of Ricardian households and habit of Non-Ricardian households are 0.7 and 0.3 , respectively.

The calibration of the tax system points to heavy taxation on capital and labor income, where different rates are considered for each labor category. The tax rate on consumption $\tau^{C}$ is equal to 0.17 , while the tax rate on physical capital $\tau^{K}$ is 0.33 , consistently with the calibration used in the Italian version of QUEST III (D'Auria et al., 2009). For the tax rates on wage income, the calibration is based on data taken from RFCL-ISTAT 2008. In particular, the average legal tax rate on labor income paid by skilled employees is equal to 0.27 , that for the unskilled is set at 0.24 , for the self-employed is 0.26 , and for the atypical workers is 0.24 . The social contribution rates paid by firms and workers are set, respectively, at 0.33 and 0.09 as legal rates of contribution. 


\section{Appendix D - Diagnostic tests}

Figure D1 traces the graph of historical and smoothed variables. The black dotted line represents the observed data, while the red line represents the estimate of the smooth variable derived from the Kalman smoother at the posterior mean. In the case of no measurement error, both series are identical.
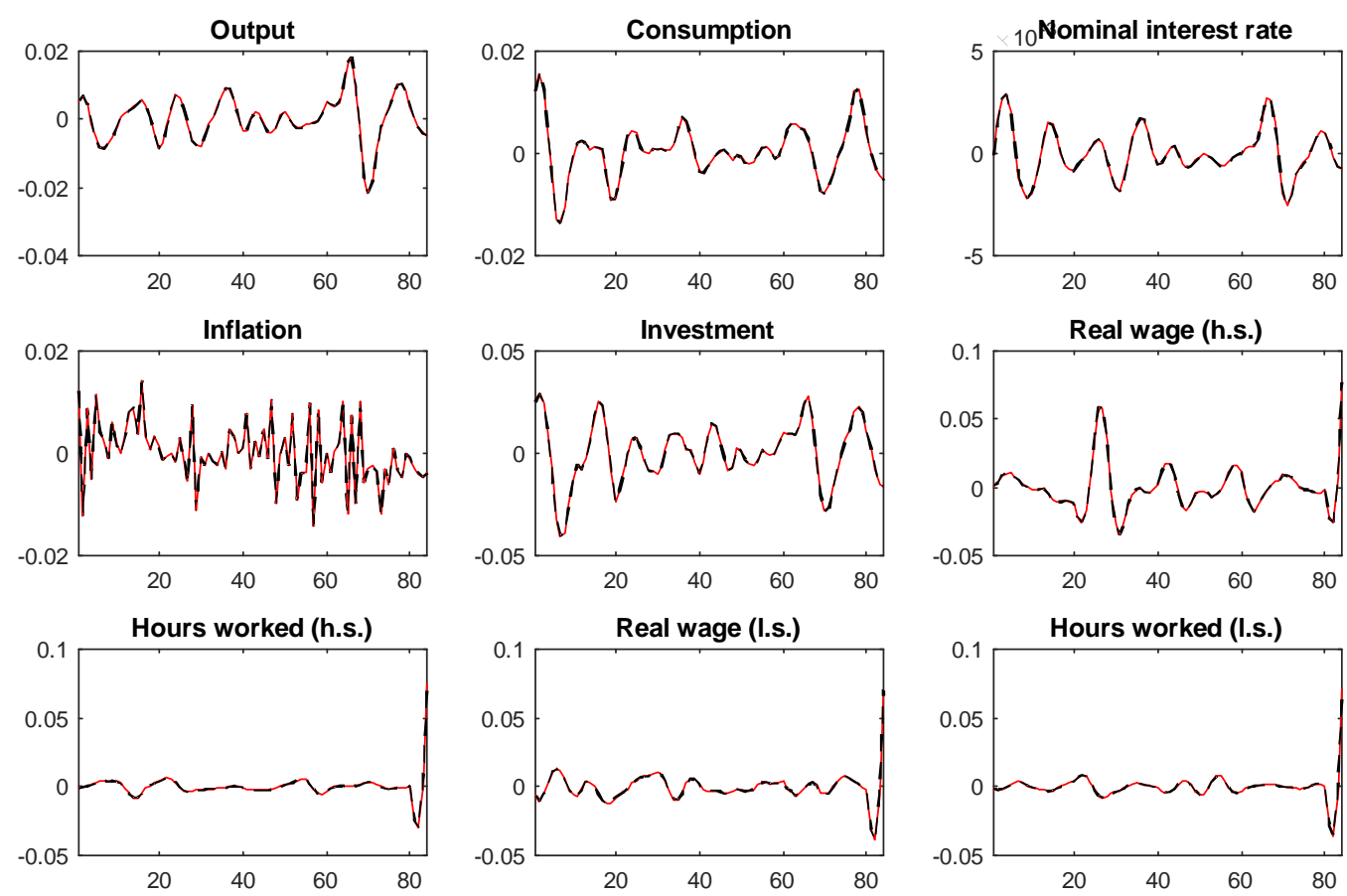

Figure D1 - Historical and smoothed variables

Figure D2 plots the smoothed shocks. The black line represents the estimate of the smoothed structural shocks derived from the Kalman smoother at the posterior mean. 

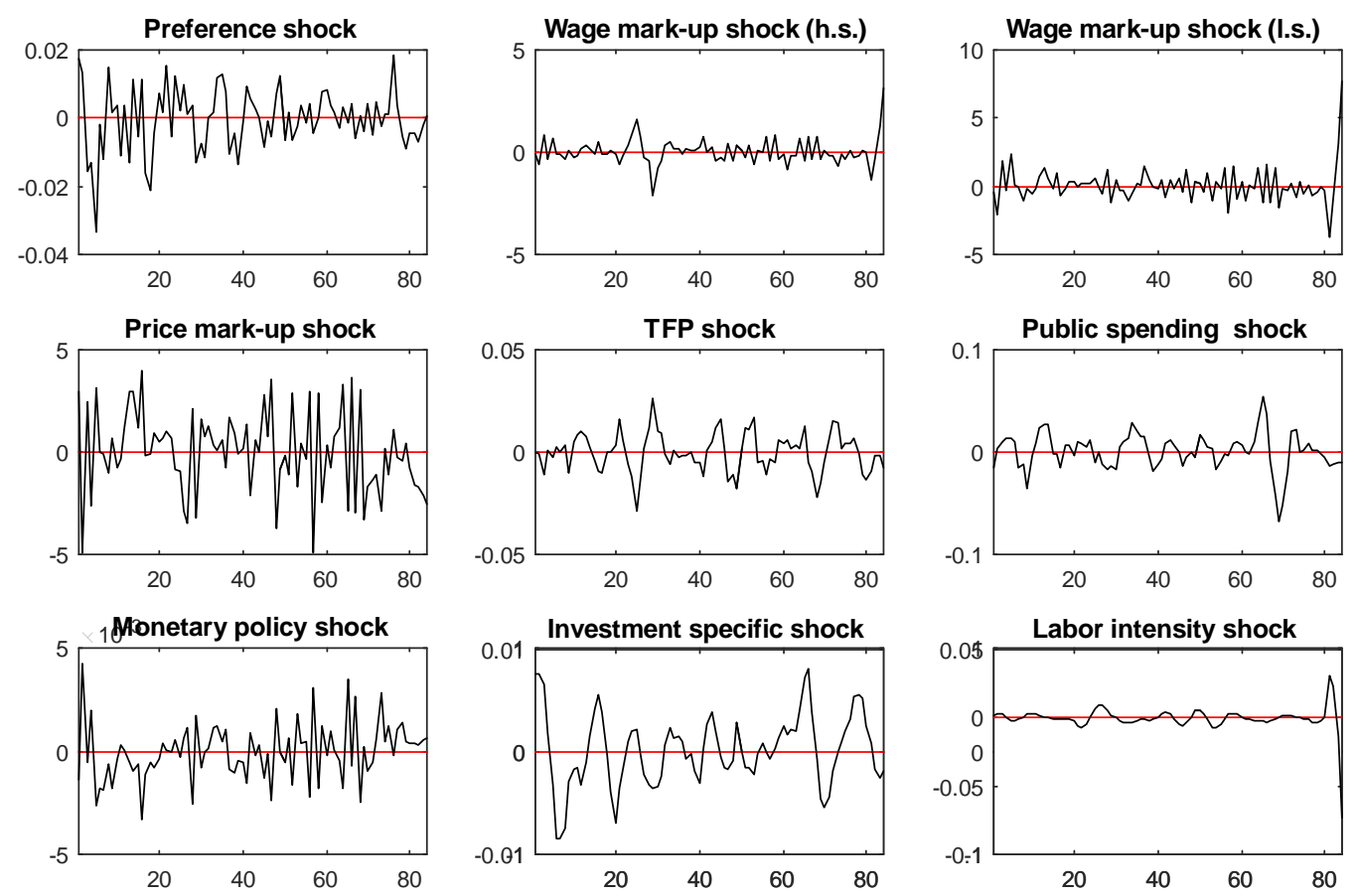

Figure D2 - Smoothed shocks

\section{References}

Adolfson, M., M. K. Andersson, J. Lindé, M. Villani, and A. Vredin (2007), "Modern forecasting models in action: Improving macroeconomic analyses at central banks," International Journal of Central Banking, 3(4): 111-144.

Albonico, A., A. Paccagnini, and P.Tirelli (2017), "Great recession, slow recovery and muted fiscal policies in the US," Journal of Economic Dynamics and Control, 81: 140-161.

An, S., and F. Schorfheide (2007), "Bayesian Analysis of DSGE Models," Econometric Reviews, 26(2-4): 113-172.

Annicchiarico, B., F. Di Dio, F. Felici, and L. Monteforte (2013a), "IGEM: A dynamic general equilibrium model for Italy," Working Papers 4, Department of the Treasury, Italian Ministry of the Economy and of Finance.

Annicchiarico, B., F. Di Dio, and F. Felici (2013b), "Structural reforms and the potential effects on the Italian economy," Journal of Policy Modeling, 35(1): 88-109. 
Annicchiarico, B., F. Di Dio, and F. Felici (2015), "Fiscal devaluation scenarios: A quantitative assessment for the Italian economy," Open Economies Review, 26(4): 731-785.

Brooks, S. P., and A. Gelman (1998), "General methods for monitoring convergence of iterative simulations," Journal of computational and graphical statistics, 7: 434-455.

Christiano, L. J., M. Eichenbaum, and C. L. Evans (2005), "Nominal rigidities and the dynamic effects of a shock to monetary policy," Journal of Political Economy, 113(1): 1-45.

Christiano, L., M. Traband, and K. Walentin (2010), "DSGE models for monetary policy analysis," in Friedman B. and Woodford M., editors, Handbook of Monetary Economics, Elsevier, Amsterdam, the Netherlands.

Christiano, L. J., M. Eichenbaum, and M. Trabandt (2017), "On DSGE models," Journal of Economic Perspectives, forthcoming.

Coenen, G., and R. Straub (2005), "Does government spending crowd in private consumption? Theory and empirical evidence from the euro area," International Finance, 8(3): 435-470.

Coenen, G., Erceg, C. J., Freedman, C., Furceri, D., Kumhof, M., Lalonde, R., and Mursula, S. (2012). "Effects of fiscal stimulus in structural models." American Economic Journal: Macroeconomics, 4(1), 22-68.

D'Auria, F., A. Pagano, M. Ratto, and J. Varga (2009), "A comparison of structural reform scenarios across the EU member states: Simulation-based analysis using the QUEST model with endogenous growth," European Economy - Economic Paper No. 392.

Di Bartolomeo, G., and L. Rossi (2007), "Effectiveness of monetary policy and limited asset market participation: Neoclassical versus Keynesian effects," International Journal of Economic Theory, 3(3): 213-218.

Di Bartolomeo, G., L. Rossi, and M. Tancioni (2011), "Monetary policy, rule-ofthumb consumers and external habits: A G7 comparison," Applied Economics, 43(21): 2721-2738.

Fernández-Villaverde, J. (2010), "The econometrics of DSGE models," SERIEs Spanish Economic Association, 1(1): 3-49.

Ferrara, M., and P. Tirelli (2017), "Equitable fiscal consolidations," Economic Modelling, 61(1): 207-223. 
Forni, L., L. Monteforte, and L. Sessa (2009), "The general equilibrium effects of fiscal policy: Estimates for the Euro area," Journal of Public Economics, 93(34): $559-585$.

Galí, J. (1999), "Technology, employment, and the business cycle: Do technology shocks explain aggregate fluctuations?," American Economic Review, 89(1): 249-271.

Gali, J., J. Lopez-Salido, and J. Valles (2007), "Understanding the effects of government spending on consumption," Journal of the European Economic Association, 5(1): 227-270.

Iskrev, N. (2010), "Local identification in DSGE models," Journal of Monetary Economics, 57(2): 189-202.

Katz, L. F., and K. M. Murphy (1992), "Changes in relative wages, 1963-1987: Supply and demand factors," Quarterly Journal of Economics, 107(1): 35-78.

Smets, F., and R. Wouters (2003), "An estimated dynamic stochastic general equilibrium model of the euro area," Journal of the European Economic Association, 1(5): 1123-1175.

Smets, F. and R. Wouters (2007), "Shocks and frictions in US business cycles: a Bayesian DSGE approach," American Economic Review 97(3): 586-606.

Schmitt-Grohé, S., and M. Uribe (2003), "Closing small open economy models," Journal of international Economics, 61(1): 163-185. 


\section{Ministry of Economy and Finance}

Department of the Treasury

Directorate I: Economic and Financial Analysis

Address:

Via XX Settembre, 97

00187 - Rome

Websites:

WWW.mef.gov.it

www.dt.mef.gov.it/it/

e-mail:

dt.segreteria.direzione1@tesoro.it

Telephone:

$+390647614202$

$+390647614197$

Fax:

$+390647821886$

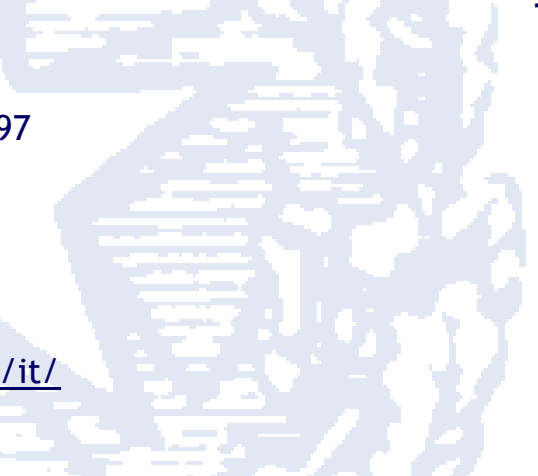

